\title{
THE ABSTRACT BOOK OF LINGUISTIC RESEARCH $2015-2017$
}

ISBN 978-969-9368-46-2
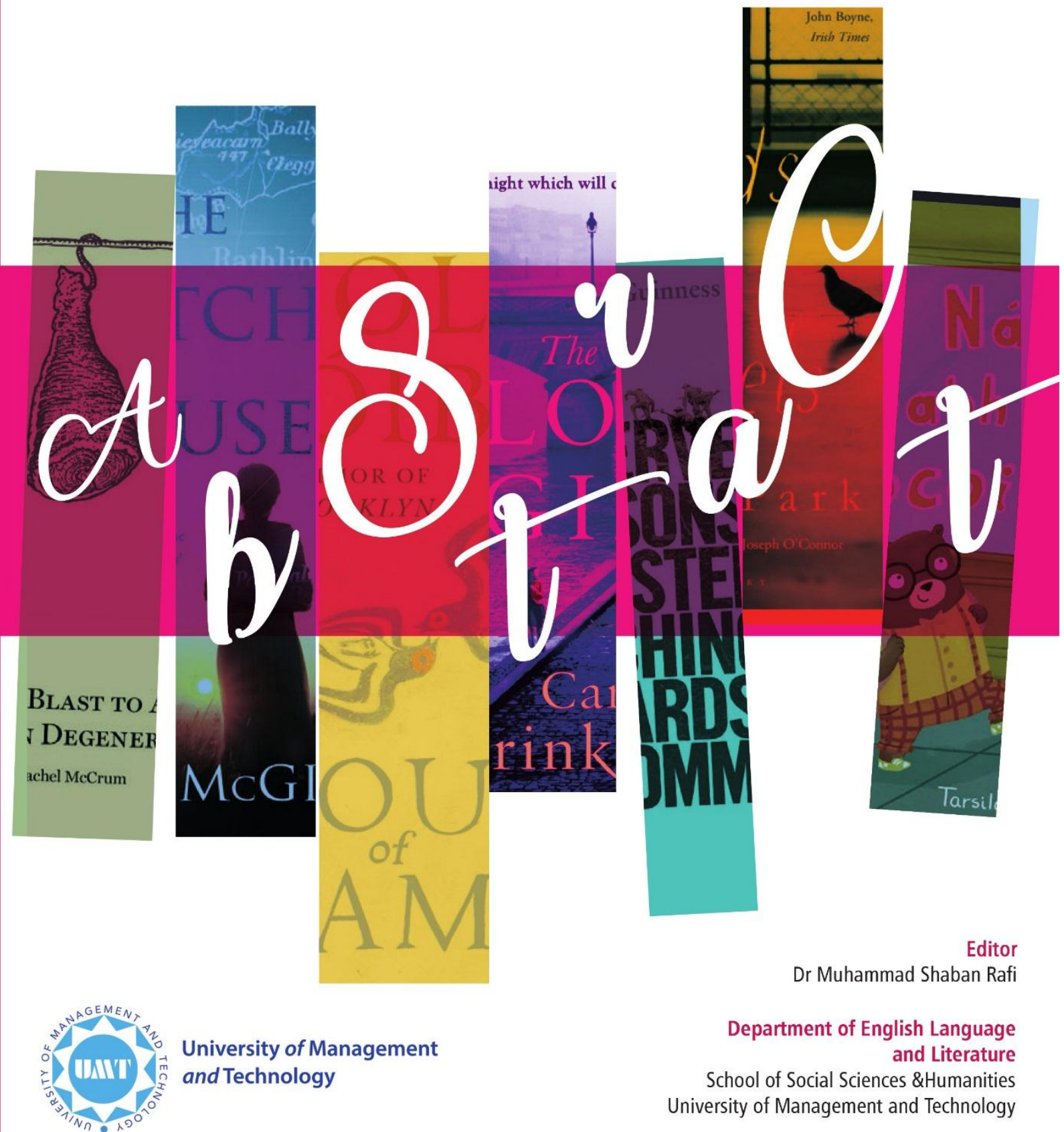

Department of English Language and Literature

School of Social Sciences \&Humanities University of Management and Technology 
(C) 2018 Selection and editorial matter, Dr Muhammad Shaban Rafi, individual abstract, the contributor. The right of editor to be identified as the author of the editorial material, and of the authors for their abstracts is asserted in accordance with the copyrights ordinance 1962 of Pakistan. Author(s) are sole responsible for statements of fact and opinion. Nobody at the Department of English Language and Literature is liable for the texts produced by authors.

All the rights reserved. No part of the abstract book of linguistic research may be reprinted or reproduced intentionally or unintentionally without the permission in writing from the Chairman, Department of English Language and Literature, University of Management and Technology, C-II Revenue Society, Johar Town, Lahore. 


\section{Editors' Information}

\section{Editor}

Dr Muhammad Shaban Rafi is Assistant Professor and Chairman at the Department of English Language and Literature, University of Management and Technology, Lahore, Pakistan. He is a faculty fellow at George Mason University, USA. He has received a vast Post-graduate research experience from Cardiff University, UK, National University of Singapore, University of Oregon, USA and George Mason University, USA. His research interest lies in language, media and discourse. He has his publications in journals of national and international standards. He is the chief editor of Linguistics and Literature Review (ISSN: 2409-109X). He has presented his papers in several national and international conferences.

\section{Assistant Editors}

Aneeka Kazmi is working as a Research Associate at the Department of English Language and Literature, University of Management and Technology, Lahore, Pakistan. Her research interests lie in feminist theory, discourse analysis, translation studies and English language teaching.

Sobia Ilyas is a Lecturer at the Department of English Language and Literature, University of Management and Technology, Lahore, Pakistan. Her research interests lie in exploring the use of language in Postcolonial and Postmodern texts.

Muhammad Saad was working as a Research Associate at the Department of English Language and Literature, University of Management and Technology, Lahore, Pakistan. His area of specialization includes word structure and formation and derivational morphology. 


\section{Research Interests of DELL Faculty}

Prof Rao Jaleel Ahmed is an Associate Professor at the Department of English Language and Literature, University of Management and Technology, Lahore. His areas of specialization are psycholinguistics, semantics and applied lexicology.

Dr Naveed Rehan is an Associate Professor at the Department of English Language and Literature, University of Management and Technology, Lahore. Her areas of specialization are creative writing and non-fiction prose.

Dr Maria Maldonado is an Associate Professor at the Department of English Language and Literature, University of Management and Technology, Lahore. Her areas of specialization are lexicology, second language acquisition, discourse analysis and language policy.

Dr Muhammad Shaban is an Assistant Professor at the Department of English Language and Literature, University of Management and Technology, Lahore. His area of specialization is language, media and discourse.

Dr Nadia Anwar is an Assistant Professor at the Department of English Language and Literature, University of Management and Technology, Lahore. Her area of specialization is African theatre and drama, adaptation studies and critical discourse analysis.

Mr Muhammad Furqan Tanvir is an Assistant Professor at the Department of English Language and Literature, University of Management and Technology, Lahore. His area of specialization is English literature and critical discourse analysis.

Mr Shahzad Ahmad is an Assistant Professor at the Department of English Language and Literature, University of Management and Technology, Lahore. His area of specialization is phonetics and phonology, morphology and syntax, lexicology and lexicography.

Ms Sobia Ilyas is a Lecturer at the Department of English Language and Literature, University of Management and Technology, Lahore. Her area of specialization is the use of language in postcolonial and postmodern texts. 


\section{List of Contents}

Acknowledgements $\quad$ i

Introduction $\quad$ ii

$\begin{array}{ll}\text { Abstracts } & 1\end{array}$

$\begin{array}{ll}\text { Phonetics and Phonology } & 2\end{array}$

"An Acoustic Phonetic Study of Six Accents of Urdu in Pakistan" (2015) by Mahwish Farooq. 3

1 Supervised by Dr Sarmad Hussain

"Description and Classification of Balti Consonants by Ghulam Abbas" (2016). 3

2 Supervised by Dr Muhammad Shaban

"Diphthong Shift in the Speech of Punjabi Speakers" (2017) by Mahwish Javaid.

3 Supervised by Prof Rao Jaleel Ahmed

"Phonemic Variations Experienced by Pakistani Immigrants in Sweden" (2016) by 4

4 Javaria Shafique. Supervised by Dr Muhammad Shaban

$\begin{array}{ll}\text { Morphology and Syntax } & 6\end{array}$

"Morphemic Structure of Lahori Mewati" (2016) by Nadia Fareed. Supervised by 7

5 Dr Muhammad Athar Khurshid

"Case Markers in Punjabi Language" (2016) by Qurat-ul-Ain. Supervised by 7

6 Dr Muhammad Athar Khurshid

"Evaluation of the Null Theories of Intra-Sentential Code-Switching: Evidence 8

7 from Balti/English Code-Switching" (2016) by Muhammad Bashir. Supervised by

Dr Arshad Ali Khan

"Grammatical Analysis of Urdu Auxiliary Verbs" (2016) by Zakia Mushtaq.

8 Supervised by Dr Sarmad Hussain

"Description and Categorization of Balti Inflectional and Derivational Morphemes" (2017) by 9

9 Iftikhar Hussain. Supervised by Dr Arshad Ali Khan

"Morphosyntactic Study of Punjabi Light Verbs"(2017) by Saba Tabassum. Supervised by

10 Dr Muhammad Athar Khurshid

"Relationship between Golden Ratio and Internalized Linguistic System of the Human Brain" 
"Semantic Evaluation of Newspaper Headlines: Media Impact of the Panama Leaks" (2017) by

"Multimodal Semiotic and Semantic Analysis of Advertising Billboards: A Pakistani

"Pragmatic Study of Heat Lightning" (2017) by Naheed Islam. Supervised by Dr Muhammad Athar Khurshid

\section{Discourse Analysis}

"The Political Rhetoric in the Pre and Post Elections (2013) Speeches of Imran Khan" (2016) by Sara Khan. Supervised by Dr Muhammad Shaban

"Hedging and Turn Taking by Pakistani Politicians: Media Discourse Analysis" (2016) by

"Dialectical Relational Analysis of Power and Resistance in the Oscar Winning Documentaries on Acid Victims and Honour Killing” (2017) by Asma Manzoor.

Supervised by Dr Muhammad Shaban

19 "Critical Discourse Analysis of the Text Produced by Hijra Community" (2017) by

Neelam Nazir. Supervised by Dr Muhammad Shaban

20 "Conversational Analysis of Five Pakistani Talk Shows" (2017) by Iram Salaam.

Supervised by Dr Muhammad Shaban

21 "Critical Discourse Analysis of Ufone Advertising" (2017) by Basharat Ali.

Supervised by Dr Muhammad Shaban

22 "Feminist Critical Discourse Analysis of Masculine Organizational Discourse: Public / Annihilation" (2017) by Syeda Aneeka Batool Kazmi. Supervised by Dr Elisabeta Zelinka

23 “Misrepresentations of Eastern Elements in Disney's Cartoon Series Aladdin (1992, 1994, 1996) A Critical Discourse Analysis Approach” (2017) by Khalid Saif Ullah. Supervised by Dr Elisabeta Zelinka

24 "The Inversion of Binaries through Violation of Gricean Maxims in The Bastard of Istanbul by 
25 "Violation of Maxims of Grice's Cooperative Principle (CP) by Pakistani Politicians in TV Talk Shows" (2017) by Safeena Qayyum. Supervised by Mr Muhammad Furqan Tanvir

26 "Deviation from Grice Maxims in the Conversation of Schizophrenic Patients: A Qualitative 22 Study" (2017) by Rabia Majeed. Supervised by Dr Muhammad Athar Khurshid

\section{Sociolinguistics}

27 "Preventive Forensic Linguistic Analysis of Urdu/English Suicide Notes" (2015) by Sumera Shan Ahmad. Supervised by Dr Muhammad Shaban

28 "Language and Identity in the Virtual Discourse" (2015) by Uzma Yaseen. Supervised by Dr Muhammad Shaban

29 "A Case Study of Haryani Language in Pakistan" (2015) by Maryam Aslam. Supervised by Dr Muhammad Shaban

30 "Stigmatization and Punjabi Language" (2015) by Naeem Arshad. Supervised by Dr Nazir Ahmad Malik

31 "A Study of Motivations of Urdu-English Code- Switching in Pakistan" (2015) by Amna Khalid. Supervised by Dr Nazir Ahmad Malik

32 "English Language Imperialism Among Young Students of Schools in Pakistan" (2015) by Naseem Akhtar. Supervised by Dr Nazir Ahmad Malik

33 "Sociolinguistic Perceptions of Punjabi and Saraiki People; The Case of Pakistan" (2016) by Malik Waseem Hasan. Supervised by Dr Nazir Ahmad Malik

34 "The Pattern of Unidirectional Code Switching Among Pakistani Languages" (2016) by Arshadullah. Supervised by Dr Nazir Ahmad Malik

35 "Lexical Inclusion of Urdu Items into Pakistani Journalistic English" (2016) by Fraaz Mahmood. Supervised by Dr Nazir Ahmad Malik

36 "A Sociolinguistic study of the replacement of vowel / a? / with /? / in Punjab" (2016) by Farhana Abid. Supervised by Dr Nazir Ahmad Malik

37 "Use of Kin Address Terms in Punjabi Speech Community" (2016) by Faryal Gill. Supervised by Dr Muhammad Shaban

38 "Social Stratification of Allophonic Variation in Punjabi Language" (2016) by Iram Amjad. Supervised by Dr Muhammad Shaban 
39 "Multilingualism and Identity Construction in the Digital Discourse" (2016)

by Ayesha Junaid. Supervised by Dr Muhammad Shaban

40 "Lexical Variation Among Punjabi Dialects as a Marker of Linguistic Boundaries in Pakistani Punjab" (2016) by Rabia Jamshid. Supervised by Dr Muhammad Shaban

41 "Urdu Newspaper Anglicized in Pakistan-A Corpus Based Study" (2016) by Muhammad Umer Anjum. Supervised by Dr Muhammad Shaban

42 "A Sociolinguistic Analysis of Language Convergence in the Speech of Housemaids of Sialkot, Punjab" (2016) by Mehr Un Nisa Baig. Supervised by Dr Muhammad Shaban

43 "Contributions and Challenges in the Implementation of Language Policies in Higher Education 33 Institutions of Punjab, Pakistan" (2016) by Aneeqa Zafar. Supervised by Dr Muhammad Shaban

44 “A Socio- Onomastic Study of Nicknaming among University Students in Pakistan" (2016) by Nida Fareed. Supervised by Prof Rao Jaleel Ahmed

45 "Nature and Frequency of Code Mixing in Spoken Discourse of Public and Private Institutions of Lahore" (2016) by Fouzia Aziz. Supervised by Dr Muhammad Athar Khurshid

46 "Sociolinguistics Challenges Faced by Baloch Students in Higher Education" (2017) by Naeem Dilpul. Supervised by Dr Muhammad Shaban

47 "Language Attitude of Adolescent Shina Speakers Towards Shina, Urdu and English" (2017) 35 by Romana Nazir. Supervised by Dr Muhammad Shaban

48 "Phonological Variations and Changes in Mewati Language" (2017) by Shahbaz Ali. 36 Supervised by Dr Muhammad Shaban

49 "Linguistic Variation as Marker of Regional Identity: A Sociolinguistic Perspective" (2017) by Bushra Nawaz. Supervised by Dr Muhammad Shaban

50 "Interpersonal Communication Barriers: A Study of Lahore Metropolitan Police" (2017) by Muhammad Irfan. Supervised by Dr Muhammad Shaban

51 "POLICEwomen or WOMENpolice: A Myth of Dual Linguistic Identity of Women in Police" (2017) by Khalid Mehmood. Supervised by Dr Muhammad Shaban

52 "Gender Differences in the Use of Linguistic Features in SMS Text Messaging of Pakistani University Students" (2017) by Kiran Aslam. Supervised by Prof Rao Jaleel Ahmed 
53 "The Role of Social Parameters in the Choice of Address Forms Used in Kinship Domain in Punjab, Pakistan" (2017) by Samrah Hidayat. Supervised by Prof Rao Jaleel Ahmed

54 "Code Mixing and Indigenization in Lahori Mewati" (2017) by Shazia Altaf. Supervised by Dr Muhammad Athar Khurshid

55 "The Effects of Urdu, Punjabi and English on Mewati Lexical Items in Pakistan" (2017) by Muhammad Kamran Arshad. Supervised by Dr Arshad Ali Khan

\section{Psycholinguistics}

56 "A Descriptive Study of the Motivation (Instrumental \& Integrative) as a Major Drive for the Learning of English Language at Graduate and Post Graduate Level in Pakistan” (2015) by Anila Imram. Supervised by Prof Rao Jaleel Ahmed

57 "The Frequency of Local and Global Errors in the Writing Skill of Undergraduate ESL Learners of Pakistan" (2015) by Muhammad Rizwan. Supervised by Prof Rao Jaleel Ahmed "The Role of Self Efficacy in Low Level Learners to Improve
by Zaheer Hussain. Supervised by Dr Muhamamd Shaban

59 "Developing Critical Thinking in Young English Language Learners" (2015) by Qurat-ul-Ain Yousaf. Supervised by Dr Asim Karim

60 "The Role of Language Transfer in Syntactic Acquisition of English Verb Particles by Pakistani by Learners" (2015) by Fariha Yasmeen. Supervised by Dr Nazir Ahmad Malik

61 "A Study of Collocation Errors Found in the Writing of Learners of English As Second Language" (2016) by Ghulam Shabbir. Supervised by Prof Rao Jaleel Ahmed

62 "Alignment Between Secondary School Certificate (SSC) English Assessments of BISEs of the Punjab and National Curriculum of Pakistan 2006" (2015) by Muhammad Saqib Zafar. Supervised by Dr Usman Khalil

63 "Correlation of Academic Performance with Extrinsic and Intrinsic Motivation" (2016) by Zoubia Ashraf. Supervised by Prof Rao Jaleel Ahmed

64 "The Frequency of errors in Articles and Propositions in the Writing Skill of Graduate ESL Learners of Pakistan" (2016) by Sumaira Akhtar. Supervised by Prof Rao Jaleel Ahmed

65 "Impact of Learner Centered Approach on Writing Skill of the Undergraduate Students of Pakistani Universities” (2016) by Maimoona Nazneen. Supervised by Prof Rao Jaleel Ahmed 
66 "Effects of an Interactive Classroom Environment on Language Anxiety Among EFL Learners" (2016) by Narjis Fatima. Supervised by Prof Rao Jaleel Ahmed

67 "Effectiveness of Online Teaching of English Language Skills at Graduate Level: A Case Study of Virtual University of Pakistan" (2016) by Afshan Asghar. Supervised by Prof Rao Jaleel Ahmed

68 "A Case Study of Language Development in 0.1-0.9 Year Old child" (2016) by Naila Shahadat. Supervised by Dr Muhammad Shaban

69 "The Impact of Formal Feedback on the Development of Writing Skills at O-Level in the Selected Private Schools in Lahore" (2016) by Ana Ramsha. Supervised by Dr Nadia Anwar

70 "Relationship between Social Stratification and Motivation to Learn English as Foreign Language" (2016) by Asma Saeed. Supervised by Dr Arshad Ali Khan

71 “A Study of Second Language Anxiety in Pakistani Learners of English" (2016) by Tooba Sahar. Supervised by Dr Nasir Abbas

72 "Use of Pakistani Newspaper Articles for IELTS Academic Writing" (2016) by Ghulam Abbas. Supervised by Mr Muhammad Furqan Tanvir

73 "Impact of Genre-based Teaching on Design Report Writing" (2017) by Tatheer Zahra. 52 Supervised by Prof Rao Jaleel Ahmed

74 "Analyzing Errors in the Use of Inflectional Morphemes by Pakistani Young Learners" (2017) by Maria Fatima Dogar. Supervised by Prof Rao Jaleel Ahmed

75 "The Use of Compliment Response Strategies Among Punjabi Speaking University Students" 53 (2017) by Summiya Azam. Supervised by Prof Rao Jaleel Ahmed

76 "An Evaluation of Assessment Tools for Secondary Level English Language Classes of All 54 BISES of Punjab: A Cognitive Approach" (2017) by Muhammad Ali. Supervised by Prof Rao Jaleel Ahmed

77 "Feedback Strategies Used by Post-graduate EFL Teachers and Students, Lahore, Pakistan" (2017) by Hafsa Karamat. Supervised by Prof Rao Jaleel Ahmed

78 "Rejuvenating Lost Communication of the Patient with Aphasia through Script Training" (2017) by Nadir Ali. Supervised by Dr Muhammad Shaban

79 "Influence of Hindi Dubbed Cartoons on the Linguistic Repertoire of Urdu/English Bilingual Children" (2017) by Zareen Ch. Supervised by Dr Muhammad Shaban 
80 "Order of Acquisition of English Vocabulary by Pakistani ESL Learners of Grade I, II and III" (2017) by Ayesha Waheed. Supervised by Dr Muhammad Shaban

81 "Phonological Impact of Hindi Cartoons on the Speech of Urdu/English Bilingual Children" (2017) by Ayesha Saddiqa. Supervised by Dr Muhammad Shaban

82 "Role of Attitude and Motivation in Enhancing Second Language Learners' Speaking Skills in Kotli Azad Kashmir University” (2017) by Misbah Shahid. Supervised by Dr Arshad Ali Khan

83 "Communicative Language Teaching Versus Transmission Models of Teaching in a Government College: An Experimental Study” (2017) by Maimoona Rana. Supervised by Dr Arshad Ali Khan

84 "A Comparative Study of TBLT Approach and Traditional Approach in English Language Teaching” (2017) by Nayab Waqas Khan. Supervised by Dr Arshad Ali Khan

85 "Examining 'Washback Effect' via Bloom's Taxonomy in a Private Pakistani School" (2017) by Ayesha Malik. Supervised by Dr Nadia Anwar

86 "Animated cartoon movies: An Innovative and Effective Teaching and Learning Tool in Enhancing the English Story Writing Skills" (2017) by Zara Saleem. Supervised by Dr Nadia Anwar

87 “Oral Skills Development in Group Work Dynamics" (2017) by Rizm Ul Zafar. Supervised by Dr Maria Maldonado

"A Study of Government Teachers' Beliefs About L2 Grammar Teaching at Secondary Level" (2017) by Sadia Nazar. Supervised by Dr Usman Khalil

\section{Linguistics and Literature}

89 "The Stylistic Analysis and Comparison of the Protagonists in 'Don Quixote' and 'Sorrows of Young Werther' and Their Socio- Cultural and Stylistic Effects” (2015) by Zujajah Naqvi. Supervised by Dr Asim Karim 
"A Stylistic Analysis of Hanif Qureshi's The Budhha of Suburbia" (2016) by Aasia Majeed. Supervised by Mr Muhamamd Furqan Tanvir

"Bakhtin Beyond The Novel: Heteroglossia, Carnival and Dialogism in 'Waiting for Godot"" (2016) by Sobia Ilyas. Supervised by Dr Muhamamd Shaban

"Preserved Versus Subverted Stereotypes of the East - West Binary in Mohsin Hamid's The Reluctant Fundamentalist (2007)" (2016) by Muhammad Hayat. Supervised by Dr Elisabeta Zelinka

"The Reluctant Fundamentalist: Identity Crises from the Global-Level to the Inter-Personal 66 94 Scale" (2017) by Kausar Mushtaq. Supervised by Dr Elisabeta Zelinka 


\section{ACKNOWLEDGEMENTS}

This abstract book showcases the output of MPhil research in the discipline of linguistics carried out from 2015 to 2017. The editors like to show their gratitude to the relevant faculty who supervised MPhil theses during this time and made the publication of this book possible. First and foremost, we like to express our sincere gratitude to Prof Dr Abdul Hameed, Dean School of Social Sciences \&Humanities, for propagating the idea of publishing the abstract book. We also like to thank Dr Naveed Rehan, Associate Professor, DELL for her valuable contribution comprising the very useful insights to improve the abstract book further. A very special note of thanks for Prof Rao Jaleel Ahmed who is the senior most faculty member and in this capacity has been a great source of inspiration, motivation and guidance. Last but not the least, all the permanent faculty members of the Department including Dr Maria Maldonado, Dr Nadia Anwar, Mr Muhammad Furqan Tanvir who not only supervised the MPhil thesis included in this abstract book but also bear the heavy burden of teaching and supervising on a regular basis with exceptional competence and surprising efficiency. We also like to say thank you to the former, adjunct and foreign faculty for their contribution in increasing the research profile of the Department. It is all the more significant and we are grateful to them for their sincere efforts in this regard. Finally, we like to acknowledge the efforts of our hardworking students whose endeavors in the field of linguistics research made the publication of this abstract book possible. It has been a pleasure for the supervisors to work in tandem with them and for the editors to make their research work known to the world at large through the compilation of this abstract book.

Dr Muhammad Shaban Rafi 


\section{INTRODUCTION}

The Department of English Language and Literature at University of Management and Technology offers an academically and professionally productive mix of programs and courses tied with both Linguistics and English Literature. MPhil in Applied Linguistics, being the most famous of our programs, is aimed to equip the students with an enviable knowledge about the structures and theories of language acquisition as well as the relationship of language with society and its various functions, especially with regard to the under-researched languages spoken in Pakistan. The emphasis is on the acquisition of latest research skills and methodologies in the field.

The discipline of linguistics has been expanding greatly since the $18^{\text {th }}$ century. However, we find its threads even beyond the 18th century into Panini's work during the 4th-6th century BC. The modern linguistics is broadly classified into formal linguistics with its various branches such as phonetics and phonology, semantics and pragmatics, morphology and syntax, functional linguistics with its focus on different aspects of the relationship between language and society explored in disciplines such as sociolinguistics, discourse analysis and language teaching that investigates with the psychological and pedagogical aspects of teaching and learning a second language in interrelated disciplines such as second language acquisition and psycholinguistics. Each of these genres maintains a plethora of scientific literature. Currently, 'linguistics' is becoming increasingly interdisciplinary. There is research on the relationship between linguistics and law, linguistics, medicine and therapy, linguistics, business and workplace, linguistics and literature, linguistics and translation and so on. Researchers have contributed vastly in these areas in scores of journals published by the top ranking university publishing houses. However, there has always been a need to conduct a research on the missing gaps, which can be identified through the exiting research on these areas.

With the proliferation of the Internet communication, the social dynamics of language that we have been debating over the years require renewed attention in the digital discourse. The communication theorists have contributed greatly on Web 1.0 (World Wide Web), Web 2.0. (Social Media Sites) and Web 3.0 (Semantic web). The volume of research that appears in journals on new media and discourse suggests emergence of a brand new discipline of linguistics (i.e., cyberlinguistics). Cyberlinguistics investigates language and its manifestations in the virtual discourse that has its real time implications. Hence the family tree of linguistics has been and will be expanding into different directions that invite researchers to contribute in these areas.

We have made applicable and publishable research the heart of learning process here because we believe in learning by doing. This abstract book will suffice to show our considerable efforts in the field of linguistics, with an emphasis on its applied and practical aspects within the Pakistani context. In this regard, the students may find it easier to write and publish their research work in areas where it is urgently needed and scarcely available such as documentation and codification of endangered languages of Pakistan, preparing grammar books and dictionaries of national and 
regional languages as well as developing their corpus utilizing digital resources, investigating linguistic communication in the multilingual and multicultural society of Pakistan in different domains such as home, academia and corporate offices; exploring the power relations among the speakers of different languages and promoting linguistic rights and identity of minority speakers, developing language policy to cater the linguistic needs of the multilingual population of Pakistan with a special emphasis on academic and scientific needs in the global context, and improving the linguistic and communicative aspects of life for the disabled.

This book comprises mostly the abstracts of theses on linguistics. The Department of English Language and Literature initiated MPhil English Literature in the year 2016 and we are hopeful that in due course of time the scholars of this program will also venture into the domain of research and will do their theses, and their abstracts will be published in the next issue. Indeed, the growing field of Pakistani literature in English offers rich avenues for study and criticism for our students. The study of traditional, canonical British and American literature has long been supplemented by the inclusion of works by non-native speakers of English from former British colonies, along with translations into English of literature from around the world. Today's globalized and interconnected world continues to bring people ever closer in terms of ideas, even as political events and worsening western economies push some of their citizens towards isolationism.

Dr Muhammad Shaban Rafi 
ABSTRACTS 
Phonetics and Phonology 


\title{
An Acoustic Phonetic Study of Six Accents of Urdu in Pakistan
}

\author{
Researcher: Mahwish Farooq \\ Supervisor: Dr Sarmad Hussain
}

\begin{abstract}
Urdu is a lingua franca, an official language (Mahmood, 2004) and the mother tongue of 7.5\% population in Pakistan (Zia, 2011). The present study carries out an acoustic phonetic analysis to find out the accent variation in Pakistani Urdu. Pakistan is a multilingual country and the purpose of this research is to analyze the influence of other languages on Urdu. This research is based on a quantitative methodology. The recording of the utterances by the speakers of Urdu, Punjabi, Sindhi, Balochi, Pashto and Saraiki languages have been collected by developing a system for online data collection. 30 speakers of each language have been enrolled voluntarily to provide recordings for speech corpus. The corner vowels from the utterances have been evaluated by comparing them with the acoustic properties. Accent differences are acoustic manifestations of differences in duration, pitch, intonation pattern and of course the difference in phonetic transcription (Yan \& Vaseghi, 2002). Since this is a first step in an acoustic phonetic study of Urdu accents, therefore only variations of vowels have been identified by measuring the formant frequencies manually in PRAAT software. The preliminary analysis of first and second formant frequencies showed the differences in the characteristics of vowels. This research has verified that the formant frequencies of vowels (as articulated by the speakers of six major languages of Pakistan) show differences and variations. This is due to the fact that Urdu is the second or third language for most Pakistani speakers (Rehman, 2002). It has also verified that some utterances show more similar values of formant frequencies (of the speakers" utterances) than others, e.g., similarities in the formant frequencies in the utterances of Urdu and Punjabi speakers. While some other show more variant and dissimilar formant frequencies as in the case of Urdu and Sindhi language speakers' utterances.
\end{abstract}

\section{Description and Classification of Balti Consonants}

Researcher: Ghulam Abbas Balti

Supervisor: Dr Muhammad Shaban

\begin{abstract}
The present study attempts to describe and classify consonants of Balti language which is spoken in Baltistan region of Gilgit-Baltistan of Pakistan. The study selected Balti language because it is one of the lesser known languages in Pakistan and no significant work on the sounds and sound system of Balti language has ever been conducted. In order to describe and classify Balti consonants, 120 different words were selected from different Balti books. These words are arranged in the form of pairs to determine phonemic or allophonic contrast between different consonant sounds of Balti. In order to provide further empirical support to the description of sounds, the study also employed acoustic analysis of Balti consonants to show their physical features by using the software PRAAT. To record the samples of different Balti consonant sounds, the researcher selected 20 native Balti speakers between the age group of 16 to 35 studying in the Govt College (boys) Model Town and University of Management and Technology, Lahore Pakistan. The physical features of the sound samples of Balti native speakers were shown in the
\end{abstract}


form of spectrograms for each and every individual sound. Articulatory and acoustic analyses of Balti consonant sounds demonstrate that there are a total of 40 consonant sounds in Balti language. Out of these 40 sounds, there are 15 stops, i.e., 3 bilabial sounds $/ \mathrm{p} /$, $\mathrm{ph} /$ voiceless and $/ \mathrm{b} /$ voiced, 3 dento-alveolar stops $/ \square /$ voiceless un-aspirated $/ \square \mathrm{h} /$ voiceless aspirated and /d/ voiced, 3 alveolar stops /t/, /th/ voiceless and /d/ voiced, 5 velar stops $/ \mathrm{k} /, / \mathrm{kh} /, / \mathrm{kr} /$ voiceless and two voiced velar stops /g/ and /gr/ and 1 uvular stop /q/, 5 nasal sounds $/ \mathrm{m} /$ voiced bilabial nasal $/ \mathrm{n} /$ voiced dento alveolar nasal $/ \mathrm{D} /, / \mathrm{n} /$ and $/ \mathrm{n} /$ velar nasal, 10 fricatives out of which 5 are alveolar fricatives /s/, / hl/, / hr / voiceless and /z/ and /r/ voiced fricatives, 2 voiced velar fricatives $/ \mathrm{x} /, / \mathrm{\gamma} /$ and 1 voiceless glottal fricative $/ \mathrm{h} /, 5$ affricates out of which 2 voiceless dento alveolar affricates $/ \mathrm{ts} /$, /tsh/, 2 voiceless palate alveolar affricates / $\mathrm{t} /, / \mathrm{t} \mathrm{h} /$ and 1 voiced affricates / $\mathrm{d} /, 1$ trill sound, 1 flap, 1 lateral and 2 glide sounds were found. All the sound samples of native Balti speakers were analyzed using PRAAT. Since different sound samples did not show any significant variation, only one of 20 sound samples recorded was presented in the form of spectrograms. Thus, the study successfully described and classified consonants of Balti language in both articulatory and acoustic terms.

\title{
Diphthong Shift in the Speech of Punjabi Speakers
}

Researcher: Mahwish Javaid

Supervisor: Prof Rao Jaleel Ahmed

\begin{abstract}
This research aims to investigate the diphthong shifts by Punjabi English speakers, who are doing leveling and simplification in the use of English inventory of sounds and words. The close observation of the lower working class reveals that the Punjabi speakers are using an admixture of the pronunciation system while speaking English words. In order to ascertain this hypothesis empirically, 60 Punjabi speakers belonging to low educated lower working class and educated upper working class have been chosen for this study in which language, class and education have been selected as variables. The results have been tested statistically. The findings suggest that the lower working class Punjabi speakers are doing diphthong shift in back diphthongs and in diphthongs /ai/, thus this diphthong shift proves to be an indicator of class stratification. On the basis of these findings some suggestions for future research have been provided.
\end{abstract}

\section{Phonemic Variations Experienced by Pakistani Immigrants in Sweden}

Researcher: Javaria Shafique

Supervisor: Dr Muhammad Shaban

\begin{abstract}
This dissertation attempted to investigate the similitude and differences of Swedish and Urdu vowel inventories for the benefit of Pakistani immigrants living in Sweden. The participants of this study were Pakistani immigrants between 25-30 years of age and were regular students of SFI (Swedish for Immigrants). They were selected by using purposive sampling technique. It is a basic requirement for immigrants in Sweden to have at least basic level of knowledge of Swedish. Considering this fact, learning Swedish is very important for Pakistani immigrants. By using the exploratory research design, comparative analysis was used to answer the research question.
\end{abstract}


Analysis showed that Urdu and Swedish were entirely different from each other phonologically and it caused differences in vowel articulations. These differences made learning difficult but some similarities were also found in the mid-rounded and back rounded vowels that provided easement to learner in learning Swedish. The results of this study manifested that Swedish government needs to draw new language learning policies for immigrants to help them to learn Swedish language (with the accurate accent). Moreover, this research study revealed that there was a great need to open new SFI institutes in every commune where people could get admission on an immediate basis. 
Morphology and Syntax 


\title{
Morphemic Structure of Lahori Mewati
}

\author{
Researcher: Nadia Fareed \\ Supervisor: Dr Muhammad Athar Khurshid
}

\begin{abstract}
Mewati language belongs to the Indo-Aryan languages of the sub-continent. Mewati language is the vernacular (non-standard dialect) of Meo or Mayo people who are the natives of Mewat. Mewat is an ancient region in India. Majority of Meo people is Muslim. Many of them migrated to Pakistan after 1947 and settled in different parts of the country. The main objective of this research is to investigate the morphemic structure of Lahori Mewati. In this regard, morphemic structure and types of morphemes, e.g., free and bound morphemes in Mewati language have been examined in the light of Farida's (2-13) theoretical framework who has adapted the model of Crowley et al. (1999) which coincides with Hockett's classification of morphological models: item-andarrangement model or (IA), item-and-process model (IP), and word-and -process model (WP). The aim of the current study is to describe the derivational and inflectional morphemic features of Mewati language. The following word classes are the focus of this study: verb, nouns, verbs, adjectives, adverbs, clitics, and postpositions, etc. Some, additional information regarding methods of compounding, reduplication, and repetition in Mewati language has also been provided to the readers. Data is collected from books, magazines, newspapers and a report on Mewati language (census of India, 2011). A qualitative and descriptive scrutiny is done by following the methodology of Farida's research methodology. This methodology inquires the role of morphemes in each process which in turn has constructed a new class of words with new meanings. For example, in Mewati language, when a morpheme /i/ is added at the end of the noun 'kaam' (work), it becomes 'kaami' which means a hard worker male;it also transforms a noun into adjective. Hence, for the illustration and examination of the morphemic structure of Lahori Mewati, tables in each section have been explained in the analysis of the data sequentially. Mewati words, in italicized form with English meaning and Urdu expression, make it easy for the non-native readers to understand Mewati dialect. A comparative study of the case markers in Mewati and Urdu languages has also been discussed in conclusion for showing similarities and differences between these two dialects while keeping in mind the end result of the research.
\end{abstract}

\section{Case Markers in Punjabi Language}

Researcher: Qurat Ul Ain

Supervisor: Dr Muhammad Athar Khurshid

\begin{abstract}
This study elaborates the present range of case markers and their organization and usage in the targeted language. It helps to suggest the range of disparity in case marking in Punjabi and offers a comprehensive explanation of how semantic case marking is used for argument charting in order to determine specific case markers with restricted semantic sense and usage along with similarities and differences in Urdu and English language. The aim of this dissertation is to detect a probable footing for an instructive study of the perceived asymmetrical case marking in this language which is provided by elaborate examples and comparisons from Urdu. The research is conducted by consulting data and presents a qualitative analysis of this aspect of Punjabi Grammar. Case marking is significant to determine the place of noun within syntactic arrangement. Sentences are
\end{abstract}


collected according to the case markers and the requirements of their analysis. This research is conducted by presenting comparison of Punjabi language and its grammar with Urdu and Punjabi and it suggests noticeable similarities and differences between these languages. This study is significant because it provides a window to Punjabi Grammar and its case markers.

\title{
Evaluation of the Null Theories of Intra-Sentential Code-Switching: Evidence from Balti/English Code-Switching
}

Researcher: Muhammad Bashir

Supervisor: Dr Arshad Ali Khan

\begin{abstract}
The present research study evaluates the empirical adequacy of the Null Theory of intra-sentential code-switching (CS) presented by Mahootian and Santorini (1996) and Chan (2008) from BaltiEnglish Code Switched Corpus. The sample consisted of 36 balanced Balti-English bilinguals which were divided into 8 groups. Conversation on specific topic was assigned to them in natural setting. The data was recorded and transcribed in Roman Script. The transcribed data was analyzed against Mahootian and Santorini (1996) and Chan (2008) models. The analysis of the data reveals that $\mathrm{N}$ and $\mathrm{V}$ being lexical heads do not determine the placement of respective complement. Thus, the corpus of Balti-English CS is not compatible to the proposals offered by Mahootian (1996) and Santorini (1996) and there are multiple instances which demonstrate the empirical inadequacy of the said model. Unlike Mahootian (1996), in Chan's (2008) model instead of lexical heads the functional category controls the head parameters values. Also, this model does not support empirical outcomes in Balti and English CS patterns. After evaluation of Mahootian and Santorini (1996) and Chan 2008 models against data from Balti English CS Corpus, it can be implied that neither lexical heads nor functional head determine the position of their complements. The placement of complements in projections within covert functional heads remains unjustified in Chan's (2008) proposal.
\end{abstract}

\section{Grammatical Analysis of Urdu Auxiliary Verbs}

Researcher: Zakia Mushtaq

Supervisor: Dr Sarmad Hussain

\begin{abstract}
This thesis examines and illustrates the existence, internal structure, syntactic arrangement and semantic contribution of Urdu auxiliaries (single to multiple in a verb phrase). The study investigates the behavior of auxiliary verbs ending with different morphemes and how these auxiliaries can be classified on the basis of different morphological forms. The different auxiliaries have been classified and enlisted in the form of tables so that one group can be clearly distinguished from the other.
\end{abstract}

The dissertation explores that syntactic places of multiple auxiliaries are generally fixed and the position of auxiliaries cannot be changed or swapped. This aspect has been explained with the help of linear examples as well as syntactic trees. It has been shown that syntactic trees can acquire 
various auxiliaries and intensifiers simultaneously which transforms the trees from simple to complex forms.

The current work also draws attention towards the semantic information Urdu auxiliaries bring with them. It attempts to describe that inflection in auxiliaries contribute to the aspectual meanings of the main verb. Moreover, it is noticed that the addition of auxiliaries does not always refer to the addition or change of meanings; it generally emphasizes or strengthens the existing interpretations. This research attempts to enlist all auxiliaries and their individual semantic properties.

\title{
Description and Categorization of Balti Inflectional and Derivational Morphemes
}

Researcher: Iftikhar Hussain

Supervisor: Dr Arshad Ali Khan

\begin{abstract}
The current study aims to describe and categorize the inflectional and derivational morphemes of Balti Language which is spoken by the people of Baltistan region of Gilgit Baltistan. Balti is one of the less documented languages in Pakistan and no remarkable documentation has been done on Balti morphology, particularly on word formation/morphemes. For this purpose, the researcher selected 200 Balti root words (nouns, pronouns and verbs) from the corpus using both naturalistic and documented sources. The selected 200 words were analyzed within the paradigm of both inflectional and derivational morphemes using the qualitative research design. All the possible inflectional and derivational markers were analyzed through different tables and their morphosyntactic and phonological constraints were also explained. Moreover, the collected data were analyzed and described in two phases. In the first phase, all the inflectional features, for example tense, case, voice, aspect, person, number, gender and mood were analyzed in order to find out all Balti inflectional morphemes. In the second phase, word category and amendment of meaning of selected root words were analyzed with the aim of finding out all Balti derivational morphemes. The study found 24 inflectional morphemes including 3 plural markers, 6 case markers, 1 gender marker, 11 tense markers, 3 mood markers and 6 derivational morphemes including 3 deverbal markers (derivation of nouns from verbs), and 3 denominal markers (derivation of adjectives from nouns).
\end{abstract}




\title{
Morphosyntactic Study of Punjabi Light Verbs
}

Researcher: Saba Tabasum

Supervisor: Dr Muhammad Athar Khurshid

\begin{abstract}
This research concentrates on the morphosyntactic aspects of light verbs in Punjabi language. The understudied South Asian language, Punjabi, manifests a productive formation of light verb constructions which are integral to the structure of the language. The usage of light verb is one of the ways of constructing complex sentential structure. Punjabi light verbs tend to combine with N, Adj, V, Adv, and prep to form light verb constructions. The present study attempts to discover the Punjabi light verbs, describe variations in their usage and to display a number of their syntactic and semantic characteristics. The differences among light verbs, dummy verbs, serial verbs, and auxiliaries have also been discussed. The present study is descriptive, corpus-based and qualitative in nature. Light verb constructions in Punjabi have been analyzed under Andrew Carnie's theoretical framework and phrase structure grammar in the light of $\mathrm{x}$-bar theory. The data for the study was collected from personal observation, Punjabi books, articles, journals, recordings, etc.
\end{abstract}

\section{Relationship between Golden Ratio and Internalized Linguistic System of the Human Brain}

Researcher: Adnan Ali

Supervisor: Dr Nazir Ahmad Malik

\begin{abstract}
This study followed a mixed approach to explore two research questions. The first was whether the movement driven phrase structures carried golden ratio at the head position in their constituency or not. The second research question was whether golden ratio was a constructive statistical regularity or not. The null hypothesis was that there was no relationship between golden ratio and internalized linguistic system (ILS) of the human brain. In order to explore the research questions, content analysis and arguments were used. In order to test the null hypothesis, 202 telegraphic speech structures by 47 toddlers aged between 24 to 30 months located in Lahore and Shakar Garh were selected as sample. 202 mature structures spoken by the parents of the same toddlers were selected as the counterpart for these telegraphic structures. The analysis of the XP elementary trees proved that golden ratio laid in the topmost constituency of $\mathrm{X}$ phrases in the premovement condition. Argument and discussion proved that golden ratio was a constructive statistical regularity in language. Quantitative data analysis comprising the ratio between the number of words in each telegraphic structure and that in each mature counterpart structure was found in the golden ratio. One sample t-test proved the high significance level of the sample structures generalizable for the population. This study concluded that there existed a strong relationship between golden ratio and ILS of the human brain.
\end{abstract}


Semantics and Pragmatics 


\title{
Semantic Evaluation of Newspaper Headlines: Media Impact of the Panama
} Leaks

Researcher: Rabia Shabbir

Supervisor: Dr Nadia Anwar

\begin{abstract}
The following research focuses on the impact of vocabulary items and language of newspaper headlines as depicted in the Panama Leaks Scam about the current Prime Minister of Pakistan and investigates to what extent the structures and style of reporting affect the perception of the readers. This study also explores to what extent the reporting on the Panama Leaks scam defames or maligns the name of the Prime Minister. Qualitative approach of data analysis has been adopted to analyze the negative impact of lexical items and structures or forms of newspaper headlines, in terms of their deep and semantic representations. Through contrastive textual analysis of the selected headlines, gleaned from the front pages of the English newspaper, The News, and Urdu newspaper, The Jung, the present study aimed at exploring the kind of textual and contextual strategies the two newspapers employed for propagating their preferred ideologies and creating negative impact on the readers about the news story. The results of the current study indicate that the writers of the headlines of both Urdu and English newspapers express the preferred ideologies of their respective publishing groups by using persuasive structures and provocative lexical items and hence manipulate the minds of the readers. However, based on the analysis of the data, it became clear that there were certain differences between the two sets of headlines (Urdu and English) in terms of their use of lexical items and semantic structures.
\end{abstract}

\section{Lexical, Semantic and Pragmatic Equivalence Gaps in Google Machine Translation Software}

Researcher: Naomi Justin

Supervisor: Dr Nadia Anwar

\begin{abstract}
This research investigates the lexical, semantic and pragmatic equivalence issues faced while translating Urdu into English language using Google Machine Translation (GMT) software. I have used content analysis technique of qualitative research to validate my corpus in isolation and with reference to the context. This has helped me to identify the equivalence issues in the translation process of GMT and its impact on the translated product.

The corpus selected for analysis belongs to different chapters of Zaviya 2 written by the well renowned intellect Ashfaq Ahmed. During the validation process, it has been identified that Google Machine Translation software has its limitations at lexical, semantic and pragmatic levels while translating from Urdu to English language. It fails to analyze the word and hence unable to transfer it equivalently and due to these limitations, at certain occurrences it remains ineffective in restructuring the sentence correctly.

Other than identifying these limitations, I have also suggested some recommendations which will help GMT software to improve its translation quality. I believe this research will contribute to help
\end{abstract}


GMT software overcome these issues at lexical, semantic and pragmatic level and help in producing more accurate translation.

\title{
Multimodal Semiotic and Semantic Analysis of Advertising Billboards: A Pakistani Perspective
}

\author{
Researcher: Touseef Younas \\ Supervisor: Dr Arshad Ali Khan
}

\begin{abstract}
Situating the current study in the paradigm of Visual Literacy, the researcher has employed the method of qualitative descriptive research to analyze advertising billboards not only to explore the meaning of signs but also to find out in what manner different types of semiotic resources with the combination of linguistic processes convey specific meaning in a particular social setup. In addition, the researcher's intention is to discover the hidden ideology of persuading and beguiling the target viewers in a particular social context with the combination of semantics and different types of semiotic resources. Before doing the analysis of advertising billboards, a detailed and meticulous literature review has been done of previous research studies in order to validate not only the importance and significance of the topic but also for highlighting and evaluating the current study from a new and different perspective. The researcher has chosen three aspects, that is 'gaze', 'salience', and 'vector' of multimodal social semiotic approach by Kress and Van Leeuwen (1990, 1996 and 2006) to explore the meaning of sign in visual composition of advertising billboards and Leech's (1981) semantic theory; associative meaning to make analysis of Urdu slogans in the wake of manipulation of language to beguile the target viewers. In this connection the researcher has analyzed 25 advertising billboards, erected on different sites of Lahore city. After analysis, it is evident that by combination of these two approaches, the producers of the advertisements beguile the target audiences' to a large extent. Besides, the combination of different semiotic resources in right direction not only creates elements of social affinity and involvement for the viewers but also clutches the attention of the target audience. The producers communicate effectively by using different colors, 3D effects, gestures, image, layout, typography and Urdu slogans. Furthermore, the research discovers how ideology is being developed and this ideology is not only changing the living standards of the general public but also shaping the new ideas related to life styles of the public.
\end{abstract}

\section{Pragmatic Study of "Heat Lightning"}

Researcher: Naheed Islam

Supervisor: Dr Muhammad Athar Khurshid

\begin{abstract}
This study aims at exploring the one-act play 'Heat Lightning' by Robert F. Carroll by applying pragmatic theories particularly observation, flouting and violation of 'Cooperative principle maxims'. According to Grice (1975), for successful communication human beings voluntarily observe certain principles, but it is a common observation that people often sacrifice these maxims. The maxims of cooperative principle are often applied on literary text to explore the possibilities of creating humor. I have investigated the flouting and violation of the maxims in the play 'Heat
\end{abstract}


Lightning' to find out why, how and at what situation characters flout or violate these principles. The technique of purposive sampling has been employed to select those utterances containing flouting and violation. The type of flouting and violation, the purpose and intention of the character and the effect that is achieved through flouting and violation is the focus of the study. The data is analyzed by applying descriptive qualitative approach as it is best suited because data is in form of words and utterances. The analysis shows that although all three characters in the play flout and violate the maxims but the in their own way. Grundy (2000, p. 81) states that an implicature is a result of an addressee drawing an inductive inference as to the likeliest meaning given in the context. The flouting on the part of the girl is in the form of the sudden emotional outbursts and is unintentional in the beginning but at the end of the play though the words are charged with emotions, it becomes intentional. The man on the other hand tries to manipulate the situation and to elicit the required information from the girl. The second man flouts just to keep the flow of conversation. The analysis further reveals that they violate the maxim to be sarcastic or to mislead others. The study is limited to a one-act play but can be helpful in shedding greater light on the meaning of the play and other literary genres through pragmatics. This kind of analysis scaffolds the reader's creativity in interpreting the play. 
Discourse Analysis 


\title{
The Political Rhetoric in the Pre and Post Elections (2013) Speeches of Imran Khan
}

Researcher: Sara Khan

Supervisor: Dr Muhamamd Shaban

\begin{abstract}
The study is a political rhetorical analysis of the pre and post-election 2013 speeches of Imran Khan. The study explores the use of five canons of Aristotelian rhetoric, i.e., Invention, Arrangement, Style, Delivery and Memory by the Pakistan politician. Also, the study presents a comparative analysis of the pre and post-election speeches. A total of 16 speeches of Imran Khan, 8 speeches from pre and post-election era each were examined to collect data. The data was divided into both numerical and narrative data sets according to themes developed based on the Aristotelian Classical Theory of Rhetoric. Frequency count for the recurrent data was also evaluated to provide an in-depth knowledge of the most recurring rhetorical device. In addition to frequency tables, the study was also illustrated with graphs to envision the reader with graphical representation of the comparative analysis of the pre and post-election data. The analysis of the data exposes that Imran Khan effectively employed the canons of Classical Rhetoric. Irnran Khan used Invention to construct arguments with assistance from the three modes of persuasion, i.e., logos, ethos and pathos. From the analysis, it was exposed that Imran Khan used logos (logic) mostly to discover and present arguments both in Pre and Post-Election speeches. Arrangement was used to organize the speech in a meaningful manner to attract the interests of the audiences. Style was employed to intensify the integrity of the arguments presented.

Moreover, the analysis revealed that among the stylistic devices, tropes were used most frequently by the speaker. The canon of delivery was employed to create speeches to be more effective for the listeners. The analysis of the speeches revealed that Imran Khan used falling and rising of intonation to make his arguments sound for his listeners. Lastly, the canon of memory showed that Imran Khan employed mnemonic devices to support his arguments.
\end{abstract}

The findings of the study revealed that Imran Khan employed Aristotelian Rhetoric successfully to present his propositions attractively among his audiences. Keeping in view its limitations, the study nevertheless contributes to the teaching of art of public speaking and inculcates the political figures of Pakistan to enhance their speech deliverance strategies.

\section{Hedging and Turn Taking by Pakistani Politicians: Media Discourse Analysis}

\author{
Researcher: Tanzeela Abbas \\ Supervisor: Prof Rao Jaleel Ahmed
}

\begin{abstract}
The present study explores the flouting of the conversational maxims by using hedging techniques and turn taking patterns by the politicians and educationists in the political talk shows. The focus is on examining how the maxim of manner and maxim of relation are flouted by the speakers in media discourse. Gender factor has also been taken into account to contextualize it in Pakistani political media discourse as different researchers have worked on it taking insight from the theory of Grice's cooperative principles. One of the researchers has worked on the exploitation of Grice's
\end{abstract}


cooperative maxims in TOEFL Listening Section by Dao Thi Van Hong. This research helps to examine how maxim of manner is hedged and the maxim of relation is flouted through turn taking devices by the speakers. Mixed method approach has been used by the researcher. The evidence of using hedges and turn taking is presented by triangulating the results. Twelve political and educational programs were selected for data analysis. The present study finds that the maxim of relation and maxim of manner were flouted by the speakers in political talk shows. Female politicians and educationists used hedging technique more than male politicians and educationists. It explores the reasons why flouting of the conversational maxims takes place by the speakers. This study also finds out that female speakers interrupt more than male speakers. Male speakers used forty two percent hedges whereas female speakers used fifty seven percent hedges. Male speaker used turn taking technique thirty seven percent and female speakers sixty four percent during communication.

\title{
Dialectical Relational Analysis of Power and Resistance in the Oscar Winning Documentaries on Acid Victims and Honor Killing
}

\author{
Researcher: Asma Manzoor \\ Supervisor: Dr Muhamamd Shaban
}

\begin{abstract}
This study aimed to explore power differential between genders by focusing on the discourses of power and resistance in Chinoy's documentary films on acid victims and honor killing. The feminists' perspective on gender and patriarchal social structure provided theoretical foundations to understand the nature of gender in relation to social institutions in Pakistan. The concept of power and resistance is delineated in the light of Foucault's theory of power to determine the power relations between men and women. The data were collected from two films 'Saving Face' and 'A Girl in the River: The Price of Forgiveness' by Shermeen Obaid Chinoy. Fairclough's version of CDA was applied to analyze selected discourses of men and women in the films. The results revealed that language is a tool to enact power relations between genders through the ideology of honor which is fluid and context specific as well as linked with other social hierarchies, for example socio-economic and educational status. Power and resistance exist together in the same body. The findings show that power is negative and productive, the former refers to oppression and the later indicates resistance. Resistance manifests positive aspect of power that contests oppression to enhance equal power relations between genders. It is hoped that this study would contribute in the existing scholarship on the nature of power and on-going research on discourses and power relations between genders.
\end{abstract}




\title{
Critical Discourse Analysis of the Text Produced by Hijra Community
}

\author{
Researcher: Neelam Nazir \\ Supervisor: Dr Muhamamd Shaban
}

\begin{abstract}
This study is an attempt to shed light on the linguistic choices of the Hijra (eunuch or hermaphrodite) communities responsible for discursive practices within their communities located mostly if not all in the suburbs of Lahore. A sample comprising 25 members of the hijra communities was selected to investigate what kind of discursive practices they carry out in their everyday interaction within their communities. The data was elicited through interviews and observations of the target communities. The analysis procedure was conceived from threedimensional model of Fairclough (2010) to unpack some discursive practices produced by them. The results show that their unique discursive practices (e.g., daira for circle, castration, singing, and dancing) in many ways different from others are characteristics of their group formation such as chandni dera, rawana dera, muhatia daira, marjaye daira, and arrwana daira. They communicate through a vernacular dialect of Punjabi, may be labeled as hijra vernacular. They claimed switching into garbled Urdu sometime for communication outside their group. Their community of practices covers registers (e.g., khol for home, luri for girl, khondi for mother, santla forclothes, jog for hair and so on) which are exclusive to them. They prefer to use highly contextual masculine and feminine pronouns (e.g. mera guru sahib for my teacher, meri behan for my sister and, mera beta formy son) to mark their group formation. Gender is not a fixed category for hijras and they use masculine and feminine pronouns according to the masculine or feminine roles assigned to them in their groups. In addition to linguistic features, they express them through paralinguistic features (e.g., clapping, facial expression, and gaze) as a meaning making source in their discourses. The study motivates future researchers to investigate how social practices are influencing linguistic choices of Hijra communities at their workplaces.
\end{abstract}

\section{Conversational Analysis of Five Pakistani Talk Shows}

Researcher: Iram Salaam

Supervisor: Dr Muhammad Shaban

\begin{abstract}
The purpose of this study is to explore the different behaviors of the participants regarding turn taking strategies and turn allocation in different talk shows. In the course of conversation analysis, the researcher examines hosts and guests' transaction of turn taking in these talk shows. Allocation of turns and the study of interruptions are part of this research. There are a number of talk shows conducted by different hosts. This research analyzes the talk of five Pakistani talk shows of different channels. The selected shows are 'Aesay nhi chalay ga' (Ptv), 'Capital talk' (Geo), 'News eye' (Dawn), 'Kal tak' (express), 'Off the record' (Ary). The selected shows are evening talk shows aired at 8:00 pm. The topic of all the selected talk shows is 'target killing in Karachi (Media workers killed' 9th September, 2015). The data was collected from aforementioned talk shows. The study shows that turn taking occurs in the conversation of these talk shows. However, many times, the rules of conversation are not obeyed by the participants. The mechanism does not occur in an orderly fashion. There are some violations in turn taking such as overlapping and interruption.
\end{abstract}


This research focuses on the conversational analysis of turn taking mechanism in the aforementioned talk shows. The analysis of turn taking mechanism consists of yielding the floor, holding the floor, taking the floor and turn allocation procedures. The research explains the types and causes of turn taking mechanism, which are mostly used in Pakistani talk shows and elaborates the cause of turn taking that occurs in conversation in these talk shows.

\title{
Critical Discourse Analysis of Ufone Advertising
}

Researcher: Basharat Ali

Supervisor: Dr Muhammad Shaban

\begin{abstract}
The world has become a global village due to the fast communication revolution. The best way of communication are the calling networks provided by different cellular networking companies. These companies such as ufone provide different packages for various types of network users especially for youth. In order to lure the youth, networking companies rely heavily on advertisements. These advertisements are designed with catchy and artificial language which attracts the target consumers through the power of discourse. These ads also promote the ideologies of love, beauty, success, patriotism and voice quality as well as the consumer and Islamic ideologies. The main purpose of this study is to raise awareness, so the consumers may not be influenced by the use of language/persuasive discourse in advertisements before using any kind of cellular networks. For this purpose, this study addressed two basic research questions. First, what type of language ufone ads are using? Second, what type of ideologies ufone ads are promoting through these ads? These questions are answered within the framework of Critical discourse Analysis. The collected data was of one type: advertisements (TVCs and print ads). It was analyzed according to Fairclough's (1989) three-dimensional approach of discourse analysis and the results were discussed in terms of discourse, ideology and power.
\end{abstract}

\section{Feminist Critical Discourse Analysis of Masculine Organizational Discourse: Public / 'Gendered' versus Private / 'Gender-Neutral' Standpoints in Osama Bin Laden's Hunt and Annihilation}

Researcher: Syeda Aneeka Batool Kazmi

Supervisor: Dr Elisabeta Zelinka

\begin{abstract}
This research aims to study the masculine organizational discourse through the conceptual framework of Feminist Critical Discourse Analysis. The study selected one of the most powerful organizations in the world, the Federal Government of the United States of America in order to analyze the discourse articulated by the U.S. policy makers on the historic(al) event of Osama Bin Laden's (OBL) annihilation. The discourse of the governmental officials was compared and contrasted with the discourse articulated by non-governmental operatives on one and the same issue. It was a gender-analytic perusal of unequal power relations between men and women displayed in the governmental versus non-governmental discourse. Techniques of textual, inter textual and social semiotic analysis as well as character analysis were deployed. As a result of the investigation it has been discovered that women have been eliminated from the organizational
\end{abstract}


discourse by deploying passive voice. Women are absent from the official narrative about OBL's hunt both verbally and physically. For example, in a seventy five minute long documentary, entitled Bin Laden: Shoot to Kill, voicing the official account of OBL's hunt and killing, women shared only seven seconds of screen time. At the other end of the spectrum, the private discourses, voiced through books, documentaries and movies, proclaim that a group of women played the key role in locating OBL's Abbottabad compound. Therefore, the study concludes that one of the leading political organizations, the Federal Government of America is gendered. It systematically facilitates men, while women are actively and deliberately eliminated from the discourses of the U.S. officials. This research has epistemologically appraised the gender inequality by probing the male dominance in the Federal Government of the United States of America as well as in Hollywood. The elimination of women from the governmental discourse as well as the objectification of women in the Hollywood movies is scrutinized in the study. My future research will focus on the reasons behind the elimination and objectification of women.

\title{
Misrepresentations of Eastern Elements in Disney's Cartoon Series Aladdin (1992, 1994, 1996). A Critical Discourse Analysis Approach
}

\author{
Researcher: Khalid Saif Ullah \\ Supervisor: Dr Elisabeta Zelinka
}

\begin{abstract}
Cartoon movies, as cinematic and cultural products, have long been the subject of academic research along the second half of the $20^{\text {th }}$ century. The present study aims to investigate the misrepresentations of Eastern cultural values in the Western cinematic discourse, which is often biased and imperialistic. The present study investigates the triangular connection among the Aladdin series, the Orient and certain Western (USA) political agendas in order to answer the research questions regarding the relationship between the Aladdin series and the Orient, different devices used to present the distorted image of the Orient and lastly the effects of the misrepresented reality on the minds of the audience. The primary texts of the present study are the three Aladdin cartoon films. Critical Discourse Analysis is used to study the phenomenon of mis(representations) of social and cultural values in the Aladdin series (1992, 1994, 1996). The selected content (text) and cultural signs (scenes and images) are analyzed through the semiotic analysis method. A considerable block of literature related to the "Disneyization" of the Middle East and the politicalcultural hegemony of America has been reviewed, in order to establish the theoretical grounds for this study. Upon a close analysis, the results of the present investigation indicate that different types of violence, bias, gender inequality and vilification of the Middle Eastern culture have been discovered in the Western cinematic discourse regarding Eastern values. In the selected primary texts cultural (mis)representations of dress codes, language symbolism, moral values and social relations are found. Therefore, the present study concludes that the Aladdin series contains misrepresentations of the Eastern cultural values as well as stereotypes regarding the Oriental realm. The Middle East is presented as inferior, over-sexualized, underdeveloped and as a dangerous place to live in. All three movies of the Aladdin series are simultaneously focused and analyzed in the present study. Its knowledge addition consists in the fact that this epistemological endeavor will be beneficial for the students of cultural and media studies as well as for the senior generations, such as their parents. They will have access to a better comprehension of the cartoons' connection to cultural values, as well as to the political agenda(s) behind them. The study contains
\end{abstract}


original work except as specified in the acknowledged citations. The present study is part of a growing body of research on cartoons in their cultural contexts. Future researchers may investigate the post 9/11 abrupt change in Disney's and Hollywood's interest to produce 'West-specific' cartoons and films. These post 9/11 cinematic products tend to focus on Western cultural values, rather than on Oriental ones.

\title{
The Inversion of Binaries through Violation of Gricean Maxims in The Bastard of Istanbul by Elif Shafak
}

\author{
Researcher: Aneeza Khan
}

Supervisor: Dr Nadia Anwar

\begin{abstract}
This thesis aims to apply the Gricean maxims on The Bastard of Istanbul (2006), a novel by the Turkish author, Elif Shafak. The researcher strived to unearth the implications of applying the Gricean maxims on the text speech of the abovementioned novel and see to what extent the violation of Gricean maxims leads to the formation of privileged binaries. The focus was on the two main characters in particular, Mustafa and his sister, Zeliha. For this purpose, an incident from the story of the novel was selected, and the speech portraying that incident was analyzed by the researcher. Content analysis was used as a linguistic tool to analyze the emerging patterns in the selected speech. The research paradigm is purely qualitative and uses content analysis as a method, taking help of its relational and conceptual parameters. The researcher argues that no potential research has been conducted on the selected novel, despite the fact that it is quite rich linguistically as well as in a literary sense. The findings suggest that the violation of the Gricean maxims does lead the characters to the formation of privileged binaries; however, it is not the sole reason for their emergence. Certain other factors like gender, social pressure, and psychological well-being of the individuals also lead to the formation of binaries based on the privileged and underprivileged constructs. The researcher is hopeful that this work would pave way for the future researchers to explore linguistic dimension of other texts.
\end{abstract}




\title{
Violation of Maxims of Grice's Cooperative Principle (CP) by Pakistani Politicians in TV Talk Shows
}

\author{
Researcher: Safina Qayyum \\ Supervisor: Mr Muhammad Furqan Tanvir
}

\begin{abstract}
This research investigates and analyzes the violation of Maxims of Grice's Cooperative Principle (CP) by Pakistani politicians in Urdu TV talk shows. Special attention is paid to politicians' deliberate violation of Maxim of Relevance and resorting to the technique of squabbling and bickering mostly to avoid referring to their incompetence and corruption. Further, the claim that the violations are intentional and purposeful, ploys on the politicians' part to neutralize potential harm to their reputations is justified by extraordinary frequency of this phenomenon as the anchors' lack of success in their overt attempts to ensure better adherence to the maxims of the said principle. Both Qualitative and Quantitative research methods are employed to analyze the participants' conversations, with tables and graphs indicating the frequency of relevant, partly relevant and irrelevant answers. The findings of the study point out that the frequency of irrelevant answers is quite high, politicians manipulate the conversation to achieve certain goals. It also highlights the fact that the conversation becomes ineffective when there is a violation of the maxims of Grice's CP. The study will be helpful for the students of media studies and language and communication as it stresses the significance of effective communication.
\end{abstract}

\section{Deviation from Gricean Maxims in the Conversation of Schizophrenic Patients: A Qualitative Study}

\author{
Researcher: Rabia Majeed \\ Supervisor: Dr Muhammad Athar Khurshid
}

\begin{abstract}
Linguistics and psychology both are concerned with locating and discovering the link between language and psychological procedures by which people of a community acquire and use language during social interaction. This research endeavors to discover the deviation of the individuals with schizophrenia in conversation from the Gricean maxims so that early detection could be feasible through the analysis of the linguistic patterns. It offers discernment into language disorder in schizophrenic sufferers including troubles in phonology, syntax, semantics, morphology and so on. Patients affected by schizophrenia have also been known to deviate from pragmatic cooperation of communication in terms of quality, quantity, relation and manner while having casual interaction with others. The study further locates the existing patterns in the talk of the sufferers as indifference to situational context, irrelevant responding, distorted intonation and absence of sequencing in the personal ideas of the sufferers that make their talk abnormal for the common people. The idea disorder is taken into consideration to be one of the most widespread reasons behind their verbal exchange impairments. Along with this notion, other theories from psycholinguistics and discourse analysis have been used to discover and explain the impairments. This discipline of research is naturally bordering both psychology and linguistics, however it has until now been overlooked by most linguists. This paper offers an overview of schizophrenia and language as an interdisciplinary field of studies, as a manner of integrating pragmatic notion with
\end{abstract}


psychological approach. For the empirical data, interviews have been conducted. This research has used a qualitative evaluation of records addressing change within the production of language as measured through verbal fluency testing, in addition to the analysis of spontaneous speech of the individuals. However, all the psychiatrists, speech therapists and the family members of the patients agreed that the sufferers with schizophrenia have several varieties of language impairments. They mentioned approximately the various styles of the deviation and the way they may be detected. This paper concludes with some of the approaches in which the study of schizophrenia may also provide new insights into the cognitive and neural structure of the language system and by improving the pragmatic abilities of the sufferers so that the rehabilitation process can be improved. 
Sociolinguistics 


\title{
Preventive Forensic Linguistic Analysis of Urdu/English Suicide Notes
}

\author{
Researcher: Sumera Shan Ahmed \\ Supervisor: Dr Muhammad Shaban
}

\begin{abstract}
The aim of this study is to suggest some recommendations for suicide prevention with the help of linguistic analysis of suicide notes. With a sudden increase in the rates of suicides in just a few decades, it has become a global issue. Almost every country of the world including Pakistan has been affected by it. Most of the world's religions and cultures are against committing suicide. That is why a number of organizations are working in different countries like Australia, USA, UK etc. for suicide prevention. Laws have been devised such as in Pakistan to discourage suicide occurrences. There is punishment with different amounts of fines or prison if someone attempts suicide but if he/she remains successful in doing so, no law can do anything. It is beyond understanding that why people commit suicide inspite of strict religious, cultural and legal obstructions? Though these factors influence rate of suicides to a great extent but why still there are suicide cases and why there is increase in them? To answer these questions, 25 suicide notes were collected from some regions of Pakistan like from Nankana Sahib, Lahore, Islamabad, Faisalabad and Mardaan. Those notes were collected from police stations, army officers, psychiatrists, judges, lawyers and affected families. Two research questions have been devised and these notes have been analyzed according to them. Quantitative paradigm was used to support the qualitative one. Extensive reading of notes pointed out emerging patterns in SNs. For example, there was a logical relationship between sentences though a few instances were also traced where it seemed that wrong or ambiguous information is provided in SNs. It shows that SCs wanted to convey something more than what is explicitly stated. Those implicit meanings can be interpreted by the readers which may help in understanding their actual reasons of committing suicides. It showed the trends of suicides in Pakistan: that which type of suicide is more common in Pakistan. Based on these above mentioned emerging patterns, relevant theories such as entailment, cooperative principle, relevance theory and Durkheim's theory of suicide have been applied on SNs. Results of the analysis showed that there are some differences in language usage of males and females in SNs. Mostly there is logical relationship between sentences from both the SNs which creates coherence within texts and also helps in having better understanding of it. There is violation of Grice's maxims most of the time. Both genders violate maxim of quality and both follow maxim of relevance while maxims of quantity and manner are violated by males only and observed by females. Analysis of implicit information shows that behind intimacy, interpersonal and economical issues actually there is society. It is the negative impact of the society on individuals which forces them to commit suicide. These reasons would not have reached such an extreme and become the cause of so many suicides if society hadn't interfered negatively. Therefore, such preventive measures should be adopted which can change society's negative influence on individuals to lessen the rate of suicides in Pakistan. It is hoped that the study would contribute to forensic linguistic analysis of suicide notes and to suicide prevention.
\end{abstract}




\title{
Language and Identity in the Virtual Discourse
}

\author{
Researcher: Uzma Yasmeen
}

Supervisor: Dr Muhammad Shaban

\begin{abstract}
Emergence of online media and mediated communications has triggered a change in the standard features of language and patterns of everyday life in society. In this global world, new networking application, for example, Twitter, Skype, Linked In, etc. are connecting human beings. However, the present study investigates how Pakistani Facebook users project their identity onto the virtual space. To investigate the subject, data from Facebook 'Profiles' and 'Wall posts' were copied and scrutinized. The participants for the present study were divided into three equal groups according to their ages: teenagers, youngsters, and adults. Moreover, males and females of each age group were equally included in the study to see differences of gender. The data were analyzed both quantitatively and qualitatively through simple computations of the content and subjective investigations by using Fairclough's three dimensional model of Critical Discourse Analysis. The findings revealed that people have a wide array of opportunities to project their real identity onto the virtual space, like self disclosure through profile, home pages, linguistic structures, and most importantly name and profile picture show who a person is. Moreover, it was found that traditional patterns of variation in socialization, self-disclosure, and communication on the basis of age and gender persist in the virtual world. Where male and female show differences in their life on Facebook, but these differences vary across participants of three age groups. Moreover, transition in life phases of adolescents, youngsters, and adults is identified through their linguistic and socialization behavior equally in the virtual space.
\end{abstract}

\section{A Case Study of Haryanvi Language in Pakistan}

Researcher: Maryam Aslam

Supervisor: Dr Muhammad Shaban

\begin{abstract}
The purpose of this study is to know the present status of Haryanvi language in Pakistan. Haryanvi speech community migrated from the current state of Haryana, India and settled across various parts of Pakistan in 1947. After migration, Haryanvi speech community eventually came in contact with various dialects and languages spoken across Pakistan. It seems as though Haryanvi has been depleting ever since. There are striking differences in the speed of change across the various linguistic levels, such as phonology, lexis, syntax and semantics. The present study explores intergenerational lexical shift in the Haryanvi language. Labov $(1963,1966)$ argues that language change can be observed through different age groups. Thus, the Apparent Time Hypothesis was considered for studying intergenerational lexical shift in the Haryanvi language. The data was collected from 60 participants belonging to three different age groups. The three age groups were composed of participants whose ages were between 20-30 years, 40-50 years, and 60-80 years, respectively. All the participants were residents of the province Punjab, which is in a way representative of the target population. A list of items of daily use along with their images was administered to elicit their responses. The study shows that there is more likely a significant lexical shift between 20-30 years old Haryanvi speakers. The second age group (40-50 years) was quite successful to retain some words e.g., Janda, Khat, Chora, Chori and so on. However, those who
\end{abstract}


were between 60-80 years seemed true representatives of the Haryanvi language because their responses were correct in all instances presented to them. There is reason to believe that the Haryanvi language would suffer badly after the death of the last person in this age group. Nevertheless, with these findings we can safely speculate that the Haryanvi language is endangered.

\title{
Stigmatization and Punjabi Language
}

Researcher: Naeem Arshad

Supervisor: Dr Nazir Ahmad Malik

\begin{abstract}
The purpose of the study is to examine the linguistic scenario of Punjabi language in Pakistan and the social milieu which is not favorable for it. Punjabi is being stigmatized in our society. To find out how something becomes stigma, Goffman's (1963) theory of social stigma and Link and Phelan's (2001) model of social stigma have been applied. It has been explored that Punjabi language has never been patronized politically, economically and religiously by the Muslims in the sub-continent and this attitude is still persisting in Pakistani Punjab. The discouraging auspice of these social institutions has not allowed Punjabi to flourish and become a prestigious language, rather it has been reduced to a stigma. The pages of linguistic history of Punjabi have been leafed through in this context. For real life data, questionnaires were filled and gathered from 50 graduates of the University of Punjab to judge their attitude towards Punjabi language. The results of these questionnaires confirm that Punjabi is being stigmatized. Punjabi has become a stigma and is being treated as an inferior language by Urdu and English speaking classes in Pakistan. Goffman's (1963) theory of social stigma and Link and Phelan's (2001) model of social stigma appropriately fit on Punjabi which has been transformed into a stigmatized thing from a normal thing.
\end{abstract}

\section{A Study of Motivations of Urdu-English Code-Switching in Pakistan}

\author{
Researcher: Amna Khalid \\ Supervisor: Dr Nazir Ahmad Malik
}

\begin{abstract}
English to Urdu code-switching and code-mixing is a very common phenomenon in Pakistani society. The linguistic behavior of code-switching has different motivations and reasons behind it. This study attempts to investigate the social motivations of Urdu-English code-switching. It tries to find out the answer of the question that, 'Why do people like to do English-Urdu code-switching in their daily conversation?'. This study shows that code-switching is not a meaningless linguistic activity rather it has some purposes and functions during communication. People do English-Urdu code-switching, with Extrinsic and Intrinsic motivations. This study also attempts to discern any relationship between type and level of motivations of English-Urdu code-switching and effects of gender and age on them. For this purpose data were analyzed both qualitatively and quantitatively. In order to carry out quantitative analysis questionnaire was used as an instrument. A t-test was applied to compare the means of males and females of young and middle-age. Two-way Anova was applied to discover the relationship between gender and age. Qualitative data was collected by conducting short interviews. The results indicate that Urdu-English bilinguals of Lahore have both extrinsic and intrinsic motivations to alter their language while speaking. However, extrinsic
\end{abstract}


motivation is more responsible for the occurrence of the phenomenon of code-switching and there is no significant difference between males and females regarding their overall extrinsic and intrinsic motivation to do English-Urdu code-switching. The results also show that people of young age are more motivated (extrinsically \&intrinsically) to do code-switching than people of middle-age. This study reveals that speakers do code-switching systematically. It is not a meaningless linguistic behavior. Speakers carry out code-switching, out of necessity as well as to facilitate communication.

\title{
English Language Imperialism among Young Students of Schools in Pakistan
}

\author{
Researcher: Naseem Akhtar \\ Supervisor: Dr Nazir Ahmad Malik
}

\begin{abstract}
Worldwide spread of English as a lingua franca has given rise to the demand of English language learning and teaching all over the world including Pakistan. Phillipson (1992) termed this phenomenon of expansion of English as linguistic imperialism (henceforth LI). The purpose of the study is to explore the effects of English language imperialism (hence forth ELI) on young students of schools in Pakistan. The researcher selected 90 students of grade 10 from three schools of Lahore; two English medium and one Urdu medium. Male and female students were given equal representation to avoid gender biased research. The data were collected using two tools; a questionnaire and a close ended collective interview. The data were analyzed using SPSS. Different tests like ANOVA, Independent t-test, T test (post- hoc) and Chi-square tests were applied to discover the effects of ELI. The results show that English language imperialism is affecting the young students of schools in Pakistan. It further explores that though ELI has affected students of all the three schools yet there is a variation of degree among them. The students of English medium schools are more influenced by the effects of ELI.
\end{abstract}

\section{Sociolinguistic Perceptions of Punjabi and Saraiki People: The Case of Pakistan}

\author{
Researcher: Malik Waseem Hasan \\ Supervisor: Dr Nazir Ahmad Malik
}

\begin{abstract}
In today's world where distances are getting shorter day by day, communication is playing a pivotal role in sharing one's views with others. Language is a distinct attribute of human beings which facilitates the members of society to use it for the purpose of communication. More specifically, the aim of this study is to unravel the truth behind language desertion by looking at the Punjabi and Saraiki speaking people's attitudes and perceptions towards speaking their native languages and to further explore their usage by the native speakers in their family and social circle. Semi-structured interviews have been conducted from 20 Punjabi and 20 Saraiki participants to explore the perceptions of Punjabi and Saraiki people regarding sociolinguistic issues in Pakistani context. The findings reveal that Punjabi and Saraiki do not have any significant differences when it comes to loyalty towards the native language. Among almost all Punjabi and Saraiki speakers, Urdu and English are the official medium of communication at official places such as offices,
\end{abstract}


schools and formal events. It has been noticed that both Punjabi and Saraiki participants use their native language in informal domains such as talking to native friends, relatives, families and when attending some rituals (marriages, traditional dresses, Eid gatherings, poetry). The future research direction and limitations have also been provided in the thesis.

\title{
The Pattern of Unidirectional Code Switching among Pakistani Languages
}

Researcher: Arshadullah

Supervisor: Dr Nazir Ahmad Malik

\begin{abstract}
The present study deals with the pattern of code switching among four target languages, English, Urdu, Punjabi and Pashtu by setting them into four pairs. It attempts to explore the social factors which lead the bilinguals to switch or not within these pairs of languages. The sample comprised six competent bilingual speakers selected randomly and engaged in conversation for at least 50 minutes with the help of 'the friend of a friend' approach. The bilingual speakers' interactions were recorded in their respective pair of languages by ensuring paradox observance as naturally occurring data was required. 50 minutes for each interaction of each pair of language were selected, and then the selected sample was transcribed in complementiser phrases (CPs) by using Roman alphabets to analyze the pattern of code switching which existed within the pairs. The analysis of the CPs shows that socio-cultural factors were the main stimulus which influenced the interlocutors to adopt code switching in each pair.
\end{abstract}

\section{Lexical Inclusion of Urdu Items into Pakistani Journalistic English}

\author{
Researcher: Fraaz Mahmud \\ Supervisor: Dr Nazir Ahmad Malik
}

\begin{abstract}
Today's media has changed considerably as compared to the past due to speedy progress in the means of communication. In a similar vein, the language of media has become global and many languages are being intermingled in order to cater to the needs of a globalized audience. In this project, the main aim of the writer is to explore the phenomenon of lexical inclusion in general English and then do the same with reference to journalistic communication. The case under study is of the Pakistani Journalistic English (PJE) which is experiencing the inclusion of many words from the native language - Urdu. The overall intention of the writer is to see the behavioral aspects associated with this lexical inclusion. For this purpose, the researcher explored the existing literature on the topic of borrowings and lexical inclusion with a focus on journalism. The researcher adopted the primary research question to cover the gaps existing in the literature. For this purpose, the researcher created a structured questionnaire and circulated it among the respondents. The main characteristic of this research is that it has dealt with the readers and writers separately by allowing them to give their opinion correspondingly in the separate sections in the questionnaire. It has been concluded in the research that the writers use such lexical inclusion in order to attract more readers as the majority of Pakistani public is not sufficiently well versed in English and understands its meanings fully. On the other hand, the readers also want to fully understand the writings in English. This can be a potential source to get higher number of customers for the English newspapers and viewers for the TV.
\end{abstract}




\title{
A Sociolinguistic Study of the Replacement of Vowel /a:/ with /æ/ in Punjab
}

Researcher: Farhana Abid

Supervisor: Dr Nazir Ahmad Malik

\begin{abstract}
The present sociolinguistic study investigates the alternative use of the particular vowel/a:/ or /æ/ by the English speaking community of Lahore, Punjab. The study aims to explore the sociolinguistic reasons or causes of the use of a particular vowel accent, British/a:/ or American $/ æ /$ in this community.

The sample consisted of 120 individuals selected from three distinct places of Lahore, the Daewoo Express Pakistan Bus Terminal Limited, Quaid-e-Azam Library and the University of Management and Technology Library through convenient sampling. The data was collected through passage reading, the wordlist and the structured interview by using questionnaire and by audio recordings. The collected data was entered into SPSS. The crosstab tests were used to calculate the percentages and frequencies of the particular vowel. The null hypothesis regarding the higher secondary level of students and English as a medium of instruction at school level was rejected due to statistical significance $\mathrm{p} \leq 0.05$ value.

The result indicates that there are two entirely different variants of a same vowel sound /a:/or/æ/being used in the said community. Most of the population prefers to use vowel sound /a:/ or British accent as compared to vowel/æ/ or American accent. O level education and the medium of instruction at school level are the two main causes behind the usage of American accent of the English language speech community.
\end{abstract}

\section{Use of Kin Address terms in Punjabi Speech Community}

Researcher: Faryal Gill

Supervisor: Dr Muhammad Shaban

\begin{abstract}
This dissertation attempts to investigate the kin address terms of the Punjabi speech community of Sialkot, a city of Punjab, Pakistan with the help of kinship universals first proposed by Kroeber in 1929 and later upgraded by Barnard in 1978. It also aims to explore the fluidity in the use of kin address terms of Punjabi and focuses on probing the implications of the use of kin address terms in their socio-cultural perspective. The researcher used interviews and observation as research tools to investigate and collect the kin address terms of Punjabi speech community of Sialkot and explored the socio-cultural factors affecting the 'use' of these terms in the community, respectively. The fluidity in the 'use' of kin address terms of Punjabi has been investigated across the variables of age, gender and social class. Through this treatise the researcher has looked at the organization of a Punjabi family and the sociolinguistic implications of Punjabi kin address terms. It shows how members of Punjabi speech community share a linguistic repertoire and alter their speech patterns according to the specific social situation.
\end{abstract}




\title{
Social Stratification of Allophonic Variation in Punjabi Language
}

Researcher: Iram Amjad

Supervisor: Dr Muhammad Shaban

\begin{abstract}
This study examines allophonic variation in Punjabi language - spoken in the capital city of Pakistani Punjab. A sample of 72 respondents was selected from beauty parlors representing high, middle and lower class income. To reveal social stratifications (i.e., class, gender and age) in the use of prevocalic and postvocalic 14 Punjabi variants were finalized. A quantitative approach was applied to address the research questions: (a) Do the allophonic variants [b] / [v] mark social stratification at the word onset position? (b) Do the allophonic variants [z] / [j] mark social stratification at the word coda position? (c) Whether or not females use the standard allophonic variants $[\mathrm{b}]$ and $[\mathrm{z}]$ more than males?, and (d) What is frequency of the use of allophonic variants [b] and [v] and [z] and [j] between parlor goers of (16 - 30 years old), (31 - 45 years old) and (46 - 60 years old) Also, Chi-square was measured to investigate the association between social stratification and the use of allophones. The present study finds that the use of allophones at least in the beauty parlors of Lahore city mark social stratifications. While mapping out the allophonic usage, different respondents were found using different word variants or two lexical items with similar semantic representation. Hence, social variability of the people of Lahore city who frequently visit beauty parlors can be reflected through Punjabi allophony. This study will hopefully motivate future researchers to extend social stratification research whose subject-matter has been largely English to other languages.
\end{abstract}

\section{Multilingualism and Identity Construction in the Digital Discourse}

Researcher: Ayesha Junaid

Supervisor: Dr Muhammad Shaban

\begin{abstract}
This study explores how multilingual internet users construct power relations and social identities in the digital discourse. It explores the factors that reflect gender identities in the digital discourse. In this regard, gender differences are marked on the basis of the use of speech acts, politeness and face deployment. By using the ethical frame work suggested by Mann and Stewart (2000), the data is collected from 1028 participants from five different forums. The analysis of data is carried out by mix method approach. The focus of this study is on the comparative analysis of the speech acts used by males and females on Facebook wall. Gender boundaries are examined on the basis of differences in the use of speech act kinds, politeness and face deployment in five different contexts. The data is collected in natural form and is analyzed by using Searle and Austin's framework of speech acts correlated with Brown and Levinson's politeness theory and Goff man's use of face. This study reveals linguistic patterns that determine power relations and social identities in the digital discourse. The study reveals the alignment of users' personal and collective identities at local as well as global discourses. The results show significant differences between genders in the use of speech acts, politeness, Face, Negative Face Threatening Acts, Face Threatening Acts, Face Saving Acts and Miscellaneous Category. However, no difference between genders was found in the use of Face Invading Acts, Positive Politeness and Positive Face Threatening Acts. It is hoped
\end{abstract}


that the patterns found in this study with regard to genders' use of speech acts, politeness and face deployment in the digital discourse will continue to be relevant in the future.

\title{
Lexical Variation among Punjabi Dialects as a Marker of Linguistic Boundaries in Pakistani Punjab
}

\author{
Researcher: Rabia Jamshaid \\ Supervisor: Dr Muhammad Shaban
}

\begin{abstract}
The purpose of this study is to examine the lexical variation among five Punjabi dialects such as Majhi, Doabi, Potohari, Jangli and Saraiki to find out that how far lexical variation marks the existence of regional boundaries. This study specifically examines ten Punjabi variants; Five Functional words (Kiwain / Kidan / Kaistra), (Jiwain / Jidan / Jaistra), (Hanji / Aahoo / Han), (Bhawain / Chahay / Bhalay), (Tohada / Tussanda / Taira) and Five Content words (Laal / Ratta / Suwa), (Biwi / Zanani / Zall), (Nianay / Baal / Bachay /Jatak), (Chhaiti / Jhabday / Jaldi / Trikh), (Bohta / Baon / Ghana). The data was collected from 300 middle aged (30 to 50 years old) educated (primary to bachelor) and non-educated male and female respondents belonging to five regions of Pakistani Punjab namely Bahawalnager, Multan, Lahore, Faisalabad and Khewra. 10 predetermined questions were asked to elicit information. The findings of the study suggest there is a lexical variation among Punjabi dialects. The respondents show linguistic heterogeneity to maintain their identities. Various factors such as region, gender, education, social and political background and ethnicity are also involved in defining the individual's identity. Some interesting findings add to our information like female respondents are more likely to use standard linguistic forms in their conversation as compared to men. Same is the case with educated respondents, they are conscious about their choice of variants in their conversation as compared to non-educated respondents. With these findings we can safely speculate that lexical variation marks off the resident of one region from another region. On the basis of these lexical differences among Punjabi dialects, we can mark the regional boundaries between these five specific regions of Pakistani Punjab.
\end{abstract}

\section{Urdu Newspaper Anglicized in Pakistan-A Corpus Based Study}

Researcher: Muhammad Umer Anjum

Supervisor: Dr Muhammad Shaban

\begin{abstract}
In Pakistani society, English loanwords are frequently used in spoken discourse. This has now moved to written discourse as well. This corpus-based study aimed to explore the extent of the use of English loanwords in Pakistani Urdu newspapers. An expected outcome was to generate newly verifiable data of any English words if being used in Pakistani Urdu newspapers and to find out if they had Urdu alternatives available or not. The data was collected from four Pakistani Urdu newspapers and a corpus of more than 2600 words was developed. Content categories were created and with the help of Natural language toolkit, the data was analyzed as per different classifications. The results revealed that Pakistani Urdu newspapers are being Anglicized and majority of the loanwords happen to be nouns. These loanwords do have their Urdu alternatives available. The
\end{abstract}


analysis showed that this tendency is alike in all newspapers and also it is not confined to any specific news section. The findings are certainly encouraging and paving the way for future research. It is hoped that this study will contribute to the growing literature on corpus-based Urdu studies.

\title{
A Sociolinguistic Analysis of language Convergence in the Speech of Housemaids of Sialkot, Punjab
}

Researcher: Mehr Un Nisa Baig

Supervisor: Dr Muhammad Shaban

\begin{abstract}
The purpose of this study is to explore convergence in the language of housemaids working in the Punjabi speech community. They were observed and their speech was analyzed at their homes and workplaces. The data was collected from the workplaces and homes of 30 housemaids from Sialkot, a city located in the province of Punjab. In order to find out the reasons behind the convergence, 16 landladies were interviewed. The participants of this study were Urdu/Punjabi bilinguals. Their first language was Punjabi and English was the academic language of the landladies. Descriptive approach was used to analyze the data. The study reveals that Urdu is the housemaid's language of communication at workplaces and Punjabi at their homes. They prefer to speak Urdu and try their level best to communicate with their landlady in the Urdu language. Their choice of topic also changes with the change of situation. They mix regular and irregular forms of Punjabi and English while speaking Urdu and use them in their conversation with the landlady. The number of forms code switched from English was greater than Punjabi. On the contrary, at their homes they did not mix languages. This study contributed to the field of sociolinguistics and suggested directions for future researchers.
\end{abstract}

\section{Contributions and Challenges in the Implementation of Language Policies in Higher Education Institutions of Punjab, Pakistan}

\author{
Researcher: Aneeqa Zafar \\ Supervisor: Dr Muhammad Shaban
}

\begin{abstract}
This study explores the contributions made by the Higher Education Institutions of Punjab, Pakistan to promote linguistic diversity. This research also investigates the challenges in the implementation of language policies to foster linguistic diversity in the universities located in Punjab, Pakistan. The data were collected by employing two research tools, i.e., handbooks of five higher education institutions of Punjab, Pakistan and semi structured interviews of the administrative bodies and local and foreign languages teaching faculty from five renowned universities of Punjab, Pakistan. In order to analyze the data, document analysis was employed. The findings of this study include both the contributions made for the advancement of linguistic diversity and the challenges faced in the implementation of language policies to promote linguistic diversity in the five higher education institutions of Punjab, Pakistan. Contributions consist of institutional support, meetings of concerned higher bodies involved in language policy making, development in the corpus of languages, trainings of language teachers, degree programs, diplomas
\end{abstract}


and certificates in local and foreign languages, languages as minor courses and student exchange programs whereas challenges include lack of institutional support, little development in the corpus of languages, non-transparent recruitment of language teachers, language teachers' lack of accountability, tangential trainings for language teachers, need for improvement in curriculum and polarity between local and foreign languages. It is anticipated that this piece of research would make some contributions in the area of language planning and policy making in Pakistan on tertiary level education.

\title{
A Socio- Onomastic Study of Nicknaming among University Students in Pakistan
}

\author{
Researcher: Nida Fareed \\ Supervisor: Prof Rao Jaleel Ahmed
}

\begin{abstract}
Nicknames are the voluntary linguistic choices that are made in specific contexts. They reflect the cultural norms and attitudes of a society and are strongly connected to our complex set of identities, perception of self and others. The present research analyzed the nicknames of 200 Pakistani male and female students' pre-existing friendship groups, studying at three different universities in two cities of Punjab. The data was gathered through self-administered questionnaires and follow-up interviews. The aim was to explore, categorize and analyze the nicknames structurally, functionally, and contextually. The research also explored the reasons behind nickname coinage, attitudes towards them, and their association with the bearers. The phonological analysis pattern of Kennedy and Zamuner (2006) was followed. The externally motivated nicknames were analyzed according to the propositions by Tsepkova (2013). The nicknames of females were coined out of affection and those of males were more humorous. They were sensitive to the formal and informal contexts, functioned more as address terms and were primarily positive. A majority of the nicknames was sourced in the indigenous culture and only a few were westernized. They acted as markers of the accepted and projected identity however within specific informal contexts. The research was exploratory, inferential and descriptive.
\end{abstract}

\section{Nature and Frequency of Code Mixing in Spoken Discourse of Public and Private Institutions of Lahore}

Researcher: Fouzia Aziz

Supervisor: Dr Muhammad Athar Khurshid

\begin{abstract}
The study aims to inspect the nature and frequency of English Urdu code-mixing among the male and female students of universities of Lahore with specific reference to eight parts of speech as linguistic variables. Data for this research was collected from eight major Universities of Lahore. The design was mixed method. Forty respondents were interviewed and their discourse was recorded and transcribed. The researcher counted the number of words which had been borrowed from English. Then, the researcher classified the borrowed words into parts of speech and analyzed how the respondents had tried to adjust different English parts of speech into an Urdu structure. Bar graph was used to show the difference in the frequency of mixing code, Pie graph was used to
\end{abstract}


show the differences in percentages after calculating the results for specific parts of speech. It examined the linguistic phenomenon of code mixing among the students and with respect to gender. The researcher observed substantial difference in percentage and the way each of the eight parts of speech were mixed in Urdu sentences. The most frequently mixed part of speech was noun. The rest of them were mixed in the following order: verb, adjective, pronoun, conjunction, preposition, adverb and article. It was also found that in some universities, males seemed to use nouns in code-mixing relatively more than females and in other universities females tended to use a greater degree of code-mixing. Moreover, the present linguistic environment of the country provided space for interaction between national language (Urdu) and the international language (English). Given this situation, code-mixing occurred more frequently. This study did not only focus frequency of code-mixing in the educational field, but also showed the way for research in other social domains of language to discover the code-mixing ratio.

\title{
Sociolinguistics Challenges Faced by Baloch Students in Higher Education
}

\author{
Researcher: Naeem Dilpul \\ Supervisor: Dr Muhammad Shaban
}

\begin{abstract}
This thesis explores the sociolinguistic challenges faced by students studying in higher education institutions spread over Lahore. The data was collected from Balochi speaking students registered into different degree programs at the institution of higher education in Lahore. Qualitative research design was adopted for this study. The in-depth interviewing instrument was used to collect data for the study to record the experiences of the students. Data was analyzed through thematic content. Hence, the study focused on the emerging themes in the data set. The results reveal that linguistic challenges range from pronunciation, syntax and semantic aspect of language which continuously hinder their communication in the target language (Urdu). Consequently, as the results suggest, issues of social inclusion arise when the target language proficiency is weak. The study concludes that there is a connection between social inclusion and linguistic competence. The study suggests that dominant language competence mediates between the social inclusion and multilingual or multicultural sites at the institutions of higher education in Lahore.
\end{abstract}

\section{Language Attitude of Adolescent Shina Speakers towards Shina, Urdu and English}

Researcher: Romana Nazir

Supervisor: Dr Muhammad Shaban

\begin{abstract}
We are not a sitar with a single string, and our music take more than one chord to make. We are convergences of languages and cultures, all of which are simply too lustrous to be overshadowed by a single one (Anonymous).

Gilgit-Baltistan is one of the most culturally, ethnically and linguistically diverse areas of Pakistan. Unfortunately, almost all the languages used in Gilgit-Baltistan exist only in spoken form and lack proper orthography. Furthermore, the lack of patronage from government and educational sectors
\end{abstract}


has directly affected the significance and value of these languages. The only institutionalized languages in this area are Urdu and English like the rest of the country. Keeping in view the present scenario, this study was an attempt to explore the language attitudes of a group of fifty native adolescents of Shine speech community living in Gilgit. Matched guised technique was used to elicit the unconscious responses of the respondents toward the different languages under investigation (English, Urdu and Shine languages). A brief language attitude questionnaire was also used to enhance the authenticity of the research. The collected data was statistically analyzed by using the SPSS software. The result clearly showed that the respondents were instrumentally inclined to learn English and Urdu as these languages offer more privileges and benefits as compared to Shina language. Different reasons related to the low evaluation and ratings of Shina were discussed along with the consequences. It was concluded that the vitality of Shina language may be threatened if such negative attitudes persist. Finally, some recommendations were given to uplift and safeguard the status of Shina language.

\title{
Phonological Variations and Changes in Mewati Language
}

\author{
Researcher: Shahbaz Ali \\ Supervisor: Dr Muhammad Shaban
}

\begin{abstract}
This study examines phonological variations and changes in the variety of Mewati language spoken in the districts of Lahore and Kasur. To reveal phonological variation and changes 15 variants in this variety of Mewati language were analyzed. Quantitative methodology was used in the study to answer the research questions. Mewati speech community migrated from the current state of Rajasthan, India and settled across the various districts of Pakistan in 1947. In Pakistan after migration, Mewati speech community came into contact with other languages and dialects spoken across Pakistan. Over the years, the use of Mewati language has been diminishing. Striking features have been noted at diverse linguistic levels, such as phonetics and phonology, lexicon, semantics and syntax. Labov (1966) argued that language change could be measured across diverse age cohorts. Apparent time hypothesis was considered appropriate to study variations and changes in Mewati language. The data was collected from a sample of 30 respondents belonging to various age groups. The respondents were living in both rural and urban areas. The three age groups were between 13-19 years, 20-40 years and 40-70 years respectively. The participants were the residents of Lahore and Kasur. The results showed a significant phonological variation and change in the speech patterns of 13-19 years old Mewati speakers. While, the second age group (20-40) displayed fluctuation between speech sounds in words such as chamal- جاول- جامل versus chawal. Nevertheless, the respondents in the third age group 40-70 were observed to always use original

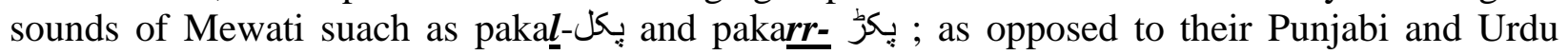
substitutes in words like the above mentioned examples. Considering the changes in the speech of the first age group (13-19 years), there is significant reason to believe that the Mewati language holds a tendency to be changed considerably in future.
\end{abstract}




\title{
Linguistic Variation as Marker of Regional Identity: A Sociolinguistic Perspective
}

\author{
Researcher: Bushra Nawaz
}

Supervisor: Dr Muhammad Shaban

\begin{abstract}
This study investigates the differences existing among three distinct dialects of the Punjabi language at phonological and morpho-syntactic level. The dialects of Majhi, Jhangvi and Saraiki are spoken in the Punjab Pakistan in Lahore, Jhang and Multan as their central cities respectively. The speakers of these dialects adhere to the features of their dialects which strongly mark their identity. This research focuses on the phonological and morpho-syntactic differences existing among Majhi, Jhangvi and Saraiki; thus it is the first of its kind in interrogating the dialectal differences among the three dialects under study. The aim of this study is to describe the prominent features of speech of Majhi, Jhangvi and Saraiki. This research hypothesizes that each of the three dialects under study carry salient phonological and morpho-syntactic features which are strong identity makers for their speakers. This study also provides useful information about the Punjabi language and its different dialects with special focus on the investigated dialects. The differences in the linguistic features of these dialects were investigated by the recording of unstructured conversations of 5 men aging 50 years or above for 30 minutes. These conversations were based on the topic 'What will be the future of our country?' The use of specific linguistic features was differentiated in the analysis. All the differences occurring in the phonetics and morpho-syntax of each dialect were compared and contrasted. The findings render the presence of salient phonological and morpho-syntactic features in the three dialects which in turn prove to be strong identity markers for their speakers as well as their speech communities.
\end{abstract}

\section{Interpersonal Communication Barriers in Police Department: A Study of Lahore Metropolitan Police}

\author{
Researcher: Muhammad Irfan \\ Supervisor: Dr Muhammad Shaban
}

\begin{abstract}
This study aims to investigate the interpersonal communication barriers that may limit or hinder interpersonal communication in police department. Several empirical studies have investigated interpersonal communication within and between the professional organizations educational institutes and other workplaces; however, few have explicitly sought to uncover the possible problematic aspects linked to the interpersonal communication barriers in the police department. A sample of 25 police officers of different ranks was selected to reveal communication barriers while disseminating and implementing security threat memos, which are composed in the English language. To find out the linguistic constraints and communication barriers, five security threat memos circulated by the higher authority over different time periods were given to the participants for reading. They were interviewed to express the barriers. Thematic analysis was used as a theoretical cover to analyze the data. Given the linguistic barriers, pronunciation, vocabulary and comprehension of the memos were among the most emerging challenges they are facing. The
\end{abstract}


finding suggests providing basic English language training to police department regarding how to communicate the exact message present in security threat memos. Future research can be undertaken to investigate the psychological and physical barriers that may limit or hamper interpersonal communication in the police department.

\title{
POLICEwomen or WOMENpolice: A Myth of Dual Linguistic Identity of Women in Police
}

Researcher: Khalid Mehmood

Supervisor: Dr Muhammad Shaban

\begin{abstract}
The purpose of this study is to explore those masculine linguistic choices which women use to construct POLICEwomen identity (construction of police identity prior to natural feminine identity) in addition to WOMENpolice identity (construction of natural feminine identity prior to police) to counter the challenges of hegemonic masculine police workplace. A purposive sample of twenty seven (27) policewomen of different cadres of Punjab Police, Pakistan serving at two police stations i.e., mixed-gender and women police stations were selected to address the research questions. Participant observation and field interviews were carried out to collect the data. Culver's (2013) four phased theory and model of Gender Identity Development of Women in the Military (GIDWM) was adapted as two phased theory and analytical model of Linguistic Identity of Women in Police (LIWP) to analyze the data. The linguistic repertoire of the participants showcased dual identities i.e., POLICEwomen and/or WOMENpolice which were observed most of the time if not always. The same results were found while analyzing the data on the basis of participants' services, seniority and contexts of duties. The study recommends gender friendly policies in the security agencies of Pakistan.
\end{abstract}

\section{Gender Differences in the Use of Linguistic Features in SMS Text Messaging of Pakistani University Students}

Researcher: Kiran Aslam

Supervisor: Prof Rao Jaleel Ahmed

\begin{abstract}
The main objective of this study is to explore gender differences in the use of linguistic features in SMS text messaging of Pakistani university students. Theoretically, the study is guided by Bodomo and Lee's model of Technology-conditioned Language Change and Use and Herring's approach of Computer Mediated Discourse Analysis. The study was quantitative in nature. One hundred students, 50 males and 50 females, were selected through purposive sampling method. They provided a corpus of 300 text messages. Two methods were used for data analysis: content analysis and descriptive statistics. Content analysis was used for classification and coding of data. Data was classified into the text messages sent by male students and the text messages sent by female students. Linguistic features were categorized into lexical features and typographical features. Lexical features were further categorized into initialism, contraction, clipping and letter and number homophones. Typographical features were further categorized into punctuation, phonetic spellings, emoticons and onomatopoeic words. Data analysis uncovered and brought forward
\end{abstract}


various linguistic features used by males and females in their text messages. It also induced the description of results and discussion on these linguistic features used in both genders' text messaging. Descriptive statistics was used to interpret data through frequencies and simple percentages. The messages were analyzed for the occurrence of lexical and typographical features and compared for differences across gender. The messages were also analyzed to identify the most frequently occurring lexical feature and typographical feature among other lexical and typographical features, in both males' and females' text messages. The findings of this study reveal the existence of gender differences in the use of linguistic features in SMS text messaging of Pakistani university students. Males tend to use more lexical features than females. Males use more initialisms, contractions and clippings whereas females use letter and number homophones more than males do. In terms of typographical features, the males tend to use phonetic spelling more than females while the females tend to use more punctuation, onomatopoeic words and emoticons than males. Among lexical features, contraction is the most frequently used lexical feature in males' text messages and letter and number homophones in females' text messages. Among typographical features, punctuation is the most frequently used typographical feature in both males' and females' text messages. This study contributes to the literature related to the study of language in terms of the use of some of the linguistic features and their variations in text messaging among males and females.

\title{
The Role of Social Parameters in the Choice of Address Forms Used in Kinship Domain in Punjab, Pakistan
}

Researcher: Samrah Hidayat

Supervisor: Prof Rao Jaleel Ahmed

\begin{abstract}
This study examines the role of social parameters in the choice of address forms used in kinship domain in Punjab, Pakistan. The study targeted 140 respondents from four different regions: Central, Northern, Southern and Western regions of Punjab, Pakistan. To reveal the association of different social factors in the choice of address forms in kinship domain, the impact of different social parameters like age, gender, social class, education, income and regional differences based on the use of kinship terms are analyzed. In order to test and investigate the impact and influence of social factors along with the regional differences in the choice of address forms in kinship domain, statistical analyses is done by applying t-test in relation to choice of address forms and ANOVA for age, income, education and social class. The study discovers that there is a strong connection of different social parameters not only with language use and practice but also in the choice and use of address forms especially in kin terms. The other related finding is that the participants belonging to young and middle categories show no significant difference with regard to the choice of address form, despite the fact that all the factors and parameters exert influence on the choices of address forms.
\end{abstract}




\title{
Code Mixing and Indigenization in Lahori Mewati
}

\author{
Researcher: Shazia Altaf \\ Supervisor: Dr Muhammad Athar Khurshid
}

\begin{abstract}
The purpose of this study was to carry out a research on sociolinguistic variables facilitating code mixing and indigenization in Lahori Mewati language. Back in 1947, Mewatis migrated from the present-day state of Haryana, India and settled themselves in different regions of newly formed Pakistan. Mewati immigrants eventually came in close contact with various dialects and languages spoken and studied in Pakistan. Such an exposure brought forward the role of some sociolinguistic variables which gauged the quality and quantity of code mixing/indigenization in Lahori Mewati dialect. Subsequently, on the basis of these variables different social groups were categorized and studied. During the course of research it was revealed that under the influence of sociolinguistic variables such as education and age, Meawti dialect of Lahore region had undergone different linguistic changes. These changes when investigated and evaluated were found particular as well as pertinent to a specific social group. On the basis of these results conclusions were iterated which correlated the type and extent of change with nature, behavior and communal preferences of a specific social group. The present study also explored intergenerational lexical shift in the Mewati language attributed to education and technological interaction. Labov $(1963,1966)$ argued that language change can be observed through different age groups. The data was collected from 36 respondents. Out of these, 18 belonged to three different age groups, i.e., 15-30 years, 31-45 years, and 46-60 years. The rest of the 18 respondents were from three educational categories, i.e., educated, semi-educated and non-educated. All the respondents were inhabitants of Lahore region. The study showed that the Mewatis of age group 46-60 years were true representatives of Mewati language who were found to be the least susceptible social group towards language change via code mixing or indigenization. On the contrary, the youth and educated class were observed with a greater rate of English and Urdu code mixing in Mewati language. This change introduced by the constant shade of sociolinguistic variables is believed to be an inescapable phenomenon of Lahori Mewati language.
\end{abstract}

\section{The Effects of Urdu, Punjabi and English on Mewati Lexical Items in Pakistan}

\author{
Researcher: Muhammad Kamran Arshad \\ Supervisor: Dr Arshad Ali Khan
}

\begin{abstract}
The purpose of this study is to investigate the effects of Urdu, Punjabi and English on Mewati lexical items in Pakistan. Mewati speech community migrated from the current state of Delhi, Haryana and Alwar in India and settled across various parts of Pakistan in 1947. Since then, Mewati speech community has come across various dialects and languages spoken in Pakistan. It seems that Mewati has been depleting ever since. There are striking differences in the speed of change across the various linguistic levels, such as phonology, lexis, syntax and semantics. The present study investigates intergenerational lexical shift in the Mewati language. Labov $(1963,1966)$ argues that language change can be observed through different age groups. Thus, the Apparent Time Hypothesis was used to study intergenerational lexical shift in the
\end{abstract}


Mewati language. The data was collected from 60 participants belonging to three different age groups. The three age groups were composed of participants whose ages were between 10-25 years, 35-50 years, and 70-90 years, respectively. All the participants were residents of the province Punjab. A list of items of daily use along with their images was administered to elicit their responses. The study shows that there is more likely a significant lexical shift between (1025) years old Mewati speakers. The second age group (35-50 years) has been quite successful to retain some words. However, those speakers who are between 70-90 years of age seem to be the true representatives of the Mewati language because their responses have been correct in all instances presented to them. There is reason to believe that the Mewati language would suffer badly after the death of the last person in this age group. Nevertheless, with these findings we can safely speculate that the Mewati language is endangered. 
Psycholinguistics 


\title{
A Descriptive Study of the Motivation (Instrumental \& Integrative) as a Major Drive for the Learning of English Language at Graduate and Post Graduate Level in Pakistan
}

Researcher: Anila Imran

Supervisor: Prof Rao Jaleel Ahmed

\begin{abstract}
The research project examines the type of motivation working as a driving force for the learning of English language in Pakistan at graduate and post graduate levels. The emerging trend of English language learning at a high rate demands an answer to questions such as why learners are so ambitious to learn this language in the presence of a national language. Secondly, if they are learning English language, what is the kind of motivation urging them to learn it. The theoretical framework of the study comprises the literature related to the famous researches of $\mathrm{R} \mathrm{C}$ Gardener and Wallace Lambert in the field of second language learning motivation. These researchers came up with the view that there are two types of motivation, i.e., Instrumental and integrative, which work as driving force for the learning of any second language. The research is descriptive in nature and data was collected through survey questionnaire. The questionnaire was adapted from Attitude motivation Test Battery AMTB developed by R. C Gardner (1985). The findings of the study show that English language learners at graduate and post graduate levels are highly instrumentally motivated. This means that they learn English language as a means to attain social, economic and educational success and not as a means in itself.
\end{abstract}

\section{The Frequency of Local and Global Errors in the Writing Skill of Undergraduate ESL Learners of Pakistan}

\author{
Researcher: Muhammad Rizwan \\ Supervisor: Prof Rao Jaleel Ahmed
}

\begin{abstract}
To investigate the nature of the writing skill problems of undergraduate learners at local and global levels, one hundred and twenty ESL male learners randomly selected from Government Postgraduate College Samnabad, Faisalabad were asked to complete three writing skill tasks. In the first task, based on fifth word deletion test in expository and narrative writing, the learners were required to provide the missing cohesive ties and grammatical items. In the second task, the learners' topic-based discussion was rated by the language experts by focusing on four analytic scoring rubrics such as cohesion, coherence, lexical range and grammatical accuracy. The third task was related to intra-sentential coherence assessment through a paragraph of jumbled sentences and the learners were asked to form it as a unified piece of discourse. The statistical outcomes of the repeated measures regarding local and global errors indicated that the learners' rate of error frequency in cohesion was $(\mathrm{N}=648)$, in coherence it was $(\mathrm{N}=816)$, in lexical range it was $(\mathrm{N}=$ $730)$ and in grammatical accuracy it was $(\mathrm{N}=784)$. The learners made $54 \%$ errors in cohesion, $68 \%$ errors in coherence, $61 \%$ errors in lexical range and $65 \%$ errors in grammatical accuracy. Thus coherence and grammatical accuracy were found to be the most problematic areas in the writing
\end{abstract}


skill of ESL learners. The study suggests changes in the current pedagogical methods, curriculum and syllabus designing.

\title{
The Role of Self Efficacy in Low Level Learners to Improve English language
}

Researcher: Zaheer Hussain

Supervisor: Dr Muhammad Shaban

\begin{abstract}
Language acquisition process is usually associated with cognitive or psychological perspectives, which promote language learning as a mental or emotional process or from sociocultural or critical perspectives. This study adopted a social-psychological perspective on language acquisition that focused on the role of self-efficacy in learning. The study investigated the self-efficacy beliefs in interaction with others in target language. The study interviewed five low-level English language learners (ELLs) from English speaking class regarding their experiences and their self-efficacy beliefs about their ability to use their English. Their views were analyzed qualitatively and five major themes were found: the expectations of English language learners, learning challenges, the participants' self-assessment of their abilities, interaction with others in target language, and the participants' learning environment. The results also explored students' expression of self-efficacy, and the ways in which their levels of self-efficacy helped or hindered their ability to become successful speakers of English.
\end{abstract}

\section{Developing Critical Thinking Skills in Young English Language Learners}

\author{
Researcher: Qurat Ul Ain Yousaf \\ Supervisor: Dr Asim Karim
}

\begin{abstract}
The study examines the extent to which critical thinking is promoted in English language teaching in Pakistan. The challenge to develop critical thinking skills in students is of dual nature, as at primary level learners are supposed to do higher order thinking in a foreign language. Though, this seems difficult, it is the right time to develop critical thinking skills among the learners. For getting teachers' responses survey method was employed using a questionnaire based on likert scale. Gap analysis between traditional modes of teaching and learning and new interactive modes of teaching and learning was done through pre-activity and post-activity by using convenient sampling. The activity of role play was used to teach the lesson. The results from the data gathered from the teachers showed mixed responses. The teachers were divided in opinion regarding critical thinking skills. The data gathered from the students showed that the learners were able to produce more new words in the post-activity as compared to the pre-activity in which some learners were not able to produce a single new word. However, the unexpected result in the survey conducted to collect data from teachers was an eye opener. The attitude of teachers should be positive towards teaching English in order to enable the learners to think critically in that language.
\end{abstract}




\title{
The Role of Language Transfer in Syntactic Acquisition of English Verb Particles by Pakistani Learners
}

\author{
Researcher: Fariha Yasmin \\ Supervisor: Dr Nazir Ahmad Malik
}

\begin{abstract}
The study investigated the learnability issues in syntactic acquisition of English verb particles (VPC) with reference to Schwartz and Sprouse's Full Transfer/Full Access hypothesis (FT/FA). It addressed the following research questions: Do Pakistani learners acquire functional structure of English verb particles which is not represented in their first language (Urdu)? Do they accommodate transferred Urdu grammar in learning English verb particles? The research is quantitative in nature and the data were collected at four Educational levels: Secondary, Higher Secondary, Graduation and Postgraduation. 200 respondents (50 students at each educational level) were selected as sample of the study from different schools, colleges and universities of Lahore city. The learners were assigned Grammatical Preference Task (GPT). It consisted of 50 paired sentences and the questionnaire developed on a five-point Likert-scale. Each paired sentence (A \& B) was followed by the five closest options. Descriptive and inferential statistics were used to analyze the data on SPSS; standard deviation (SD), chi-square, t-test and ANOVA were used to test the mean differences of the respondents. The findings showed that Pakistani learners do not demonstrate similar patterns of acquisition like L1ers, contra the Pure UG hypothesis, and L2ers are strongly influenced by L1 transfer, supporting the FT/FA hypothesis. Pakistani learners selected prepositions and particles in the same way and marked adjacent VPC as prepositions or adverbs. The learners did not have semantic and syntactic acquisition of VPC and most of them omitted verb particles due to the transfer of L1 properties. So, the increase in adjacent transparent VPC proves that Pakistani learners have acquired particle integration and the structure for transparent and adjacent VPCs as compared to split VPC.
\end{abstract}

\section{A Study of Collocation Errors Found in the Writing of Learners of English as a Second Language}

Researcher: Ghulam Shabbr

Supervisor: Prof Rao Jaleel Ahmed

\begin{abstract}
This research discovers, classifies and analyzes collocation errors made by second language learners in English composition. The participants' knowledge of collocation vocabulary in the major fields of education, politics and daily life was checked. The data was collected by using a questionnaire for teachers and by checking the written essays of the students. The data was gathered from 195 students and 100 teachers. The compiled data was analyzed in the light of qualitative and quantitative approaches by utilizing the latest version of SPSS. Results of the study confirm that there are significant collocation errors in the composition of Pakistani learners of English. Certain gender differences in demonstrating these vocabulary skills are noticeable.
\end{abstract}




\title{
Alignment between Secondary School Certificate (SSC) English Assessments of BISEs of the Punjab and National Curriculum of Pakistan 2006
}

\author{
Researcher: Muhammad Saqib Zafar
}

Supervisor: Prof Rao Jaleel Ahmed

\begin{abstract}
This study explored the extent to which there is an alignment between English Curriculum of Secondary School Certificate and assessments. To ascertain the validity and reliability of curriculum assessment tool is vital. It is important to make connections between the actual learning and the intended learning. This particular research addressed the need of identification of the degree of alignment between SSC Level assessments of English and the Curriculum of SSC. The researcher collected data through model assessments available at the website of Board of Intermediate and Secondary Education and through National Curriculum of English 2006. The data were analyzed through Webb Alignment Tool meant for finding alignment between curriculum and assessment. The research found that there was significant misalignment between curriculum and assessment of English at Secondary School Certificate Level.
\end{abstract}

\section{Correlation of Academic Performance with Extrinsic and Intrinsic Motivation}

Researcher: Zoubia Ashraf

Supervisor: Prof Rao Jaleel Ahmed

\begin{abstract}
The present study explores whether the intrinsic and extrinsic motivational constructs are two independent orientations of motivation or, alternatively, two opposite poles of a continuum. Following a quantitative research approach, data were collected from a random sample of 279 college students, using Gardener's Attitude/Motivation Test Battery (AMTB). The data were statistically analyzed using Pearson's correlation in SPSS. The results of the study suggest that different orientations of motivation, i.e., Intrinsic and Extrinsic are complementary, rather than conflicting, and they can co-exist. Additionally, the study endorses that there are no marked differences in the English language achievement of the intrinsically and the extrinsically motivated students, both male and female. Both sets of students show mixed results in terms of their marks obtained; whereas, any single orientation of motivation could not be clearly linked to any particular achievement level.
\end{abstract}

\section{The Frequency of Errors in Articles and Propositions in the Writing Skill of Graduate ESL Learners of Pakistan}

Researcher: Sumaira Akhtar

Supervisor: Prof Rao Jaleel Ahmed

\begin{abstract}
The English article system is considered very complicated for second language learners. The study is related to the research question: What is the frequency of errors of ESL graduate learners with reference to the use of (a) Articles (b) Prepositions. To investigate the nature of the writing skill
\end{abstract}


problems of graduate learners, two hundred and fifty graduate male and female learners randomly selected from four colleges and one university were asked to complete three writing skill tasks: rational deletion, fifth word deletion and open composition test. It has been discovered that article overuse and omission are the common problems for ESL learners. The findings show the wrong use of prepositions specifically 'with, in, of' and unnecessary insertion of prepositions. It is observed that errors are because of the interference of L1 in L2. Besides, the final results of the three tests show that articles (definite, indefinite, zero article) and prepositions (prepositional verbs, prepositional phrases, phrasal verbs, zero prepositions) are quite problematic for ESL learners. This study also explores the unnecessary insertion of zero article and zero prepositions. The learners usually overgeneralize the definite article and they try to use both functional words on the same patterns of L1 which ultimately cause errors. The study suggests changes in the current pedagogical methods, curriculum and syllabus designing.

\title{
Impact of Learner Centered Approach on Writing Skill of the Undergraduate Students of Pakistani Universities
}

\author{
Researcher: Maimoona Nazneen \\ Supervisor: Prof Rao Jaleel Ahmed
}

\begin{abstract}
The study investigates the effectiveness of Learner Centered Approach on the development of writing skill of undergraduate students of Pakistani universities. It is an experimental study. The participants of this study included 60 undergraduate students of first semester studying in the University of Management and Technology, Lahore. The participants were divided in two groups of 30 each. Pre-test was conducted at the start of the experiment to assess the performance of students at this stage. The experimental group was taught through Learner Centered Approach and the Control group was taught through Teacher Centered Approach. Teacher Centered based activities were used to teach writing skill to the control group during the experiment. Learner Centered based activities were used to teach writing skills to the experimental group .At the end of the experiment, a post-test was conducted in order to assess the effect of two approaches on the performance of students in writing skills. IELTS assessment method was used to assess the performance of students in the pre-test, post-test and in the activities conducted during the experiment. In order to find out the point of view of students regarding their improvement in four sub-categories of writing, post-activity questionnaire was administered after each activity conducted during the experiment. A questionnaire was administered after the experiment in order to know the point of views of the students regarding the two approaches. The quantitative analysis was done through SPSS 21. The scores of pre-test and post-test were compared to notice the approach that affected positively the writing skills of students. The results of the study show that Learner Centered Approach is more effective in developing writing skills of undergraduate students in University of Management and Technology, Lahore.
\end{abstract}




\title{
Effects of an Interactive Classroom Environment on Language Anxiety among EFL Learners
}

Researcher: Narjis Fatima

Supervisor: Prof Rao Jaleel Ahmed

\begin{abstract}
The use of English language has increased rapidly for a variety of reasons. It has become a medium of instruction. Keeping in view its importance, it is being learnt and studied as a second language in Pakistan. Many institutions are offering English language learning courses. Pakistani speakers of English language face language anxiety during its use. This feeling of anxiety may produce negative effect on learner's language acquisition. In this research, the researcher has tried to explore issues that foreign language learners face during learning English and has described how it affects their learning. The purpose of this study is to provide a view of interactive classroom environment in second language acquisition through case study of 50 undergraduate students of English language. On the basis of pre-test and post-test, it is suggested that spoken English of foreign language learners can be improved and language anxiety can be controlled with the help of classroom interaction. Levene's test was applied on the results of pre-test and post-test. The value came out to be 0.1 which is greater than 0.05 . It means the results can be generalized over the entire population.
\end{abstract}

\section{Effectiveness of Online Teaching of English Language Skills at Graduate Level: A Case Study of Virtual University of Pakistan}

Researcher: Afshan Asghar

Supervisor: Prof Rao Jaleel Ahmed

\begin{abstract}
The present study is an attempt to fulfill three main objectives: (i) compare the effectiveness of online vs. conventional mode of teaching of English Language. (ii) Determine the effects of online teaching of English Language skills in Pakistan with regard to reading and writing skills. (iii) Observe the perceptions of students' learning in virtual and conventional mode. It has been observed that online mentoring, though a recent phenomenon, has planted its roots firmly in the education sector; however, the traditional mode of learning has managed to retain its position despite the convenience of the former mode. In this context it is hypothesized that online teaching of English Language Skills at Graduate level is more effective than conventional mode. The population is the graduate students of both virtual and conventional mode. Sample size comprises 100 subjects from both the modes. Data is collected from a random sample of students covering gender, age, residence and academic background. Experimental research design is used to evaluate the English Language skills (reading and writing) of the students along with questionnaire to further assess students' performance and perceptions. Pre-test and post-test results from virtual and conventional modes are compared. The results show that students from conventional mode have better grammar, writing skills and professional efficacy; whereas students from virtual mode have better listening, speaking and reading skills. This indicates that both modes of instruction hold an advantage over the other in certain aspects. There is a significant difference in the reading skills of students between the virtual and conventional mode. According to the results, virtual
\end{abstract}


mode students have better reading skills. However, no significant difference is found between the virtual and conventional mode regarding the writing skills of the students.

\title{
A Case Study of Language Development in 0.1-0.9 Year Old child
}

\author{
Researcher: Naila Shahadat \\ Supervisor: Dr Muhammad Shaban
}

\begin{abstract}
The purpose of this study was to observe language development in a child from the birth up to the age of 9 months. The present research focused on the acquisition of human speech sounds by a child, in comparison with non-human sounds. Other than that, the study also tried to explore the effects of audio-visual elements on language development. A newborn baby boy was the subject of the current study. The total observation period of 9 months was broken down into three stages. Each stage comprised three months of child's age. The data was collected in the form of audio and video recordings, documents and interviews with family members of the subject. After observing the subject for 9 months, conclusions were drawn and compared with past studies in the same area. A child goes through many human and nonhuman sounds during his language acquisition period but as devised by Chomsky (2004) that language is innate (Chomsky, 2004), the child accepts only human speech signals to acquire language. The research concluded that both sound and image help a child to acquire a language. Individually, they cannot be beneficial in developing language in a child. Language development is a systematic process, which is achieved by a child in the early period of his or her life, no matter child comes across how many human and non-human sounds. It becomes easier for a child when he or she finds pictorial representation of what he or she listens.
\end{abstract}

\section{The Impact of Formal Feedback on the Development of Writing Skills at O- Level in the Selected Private Schools in Lahore}

\author{
Researcher: Ana Ramsha \\ Supervisor: Dr Nadia Anwar
}

\begin{abstract}
This study explores the impact of teachers' written feedback on students' English composition writing in the selected private high schools in Lahore and also examines students' attitude towards teacher feedback. A mixed method approach was used to gather both qualitative and quantitative data through the use of survey questionnaires for both students and teachers and composition essays. The study took place during the regular school year in three 0-Level classrooms. Research participants $(n=75)$ were selected using random sampling. Small scale pilot study and Cronbach's Alpha test was conducted to ensure that the research would proceed as predicted and to test the validity and reliability of the data.

Closed ended questionnaires were triangulated by analyzing real classroom composition essays. Quantitative data were collected and analyzed using Statistical Package for the Social Sciences (SPSS) and was presented using descriptive statistics with frequency and percentage of responses. The ESL composition profile constructed by Jacobs et al (1981) was used in the current research to examine the quality of learners' first draft and second draft based on the scores on accuracy,
\end{abstract}


content, expression, vocabulary and mechanical features of essay writing. The scores of learners' essay quality were measured before the feedback (first draft) and after the feedback (second draft). Two unbiased raters were requested to read and grade students' first draft and second draft using ESL composition profile to examine the quality of essays based on their scores. A paired sample T-test was run to understand whether there was a significant difference between the first draft and the second draft.

Results of the paired sample T-Test showed that the scores given by the raters increased significantly in the second draft as compared to the first draft. Teachers' comments had a constructive impact on the writing quality of the learners and a positive improvement was noticed in their performance in their post-test stage as compared to their pre-test stage. This study revealed that students get assistance even from marginal feedback. Therefore, in the light of this study it is recommended that educational institutions should work on regulating feedback practices in Pakistan and integrating multiple draft strategies in order to maximize learning.

\title{
Relationship between Social Stratification and Motivation to Learn English as Foreign Language
}

Researcher: Asma Saeed

Supervisor: Dr Arshad Ali Khan

\begin{abstract}
Disparities in social classes prevail in all human societies. Pakistani society has noticeable disparity on various grounds including income, power, prestige and sources of earning. The purpose behind this study was to investigate the relationship between social stratification and motivation to learn English as a Foreign Language (EFL). Although motivation to learn English at different levels has been widely explored by many researchers, yet the relationship between social status and language learning motivation is still needed to be explored. This study investigates the relationship social stratification has with motivation to learn English as Foreign Language as well as which social status more facilitates learning of English as Foreign Language. For this purpose, 250 English as Foreign Language learners at BS level from 7 renowned universities of Lahore were selected as participants. These learners were grouped as upper, middle and lower class learners in terms of their social backgrounds. Data was collected through their responses to a 5 point Likert scale questionnaire based on questions related to extrinsic and intrinsic motivation in EFL learning. The quantitative data was statistically analyzed through Stata. The findings reveal a significant relationship between social stratification and motivation to learn EFL. The middle social class tends to be more motivated as compared to upper and lower social classes. Administrators, policy makers and instructors may find this study useful for assessing the essential change and requirement in the field of English as Foreign Language learning. The study recommends that there should be teacher training courses to train the teachers to improve motivation for learning English and workshops should be conducted for both teachers and learners to enhance learners' motivation.
\end{abstract}




\title{
A Study of Second Language Anxiety in Pakistani Learners of English
}

\author{
Researcher: Tooba Sahar \\ Supervisor: Dr Nasir Abbas
}

\begin{abstract}
This study reports English language learning anxiety of Pakistani learners both inside and outside the classroom's context. It also focuses on the relationship between English language anxiety and learners' variables named gender, exposure to English and second language motivations. In Pakistan, researches on language anxiety are needed to understand how language anxiety works and how it can hamper the performance of students both academically and non-academically. Data were collected through the administration of a detailed questionnaire comprising 64 items based on 1-5 Likert scale. A total of 90 students who were enrolled in English programs at 5 different institutes of southern Punjab, Pakistan participated in this study. The data were analyzed using a range of statistical methods such as descriptive statistics, $T$ tests and correlation analysis. The data analyzed and elaborated the role of anxiety in learning and using English both inside and outside the classroom. Analysis of the data revealed a significant correlation between classroom anxiety and outside classroom anxiety. It also found that language anxiety was significantly correlated with second language motivations and exposure to second language. Moreover, a significant gender difference in terms of second language anxiety was also found in the present research. This study extends the current language anxiety research in Pakistan because it provides an insight on language anxiety of Pakistani learners by focusing on both classroom based anxiety and anxiety out of class. It also contributes to the existing literature in Pakistan by documenting the relationship of language anxiety with gender, exposure to English language and English language motivations.
\end{abstract}

\section{Use of Pakistani Newspaper Articles for IELTS Academic Writing}

\author{
Researcher: Ghulam Abbas \\ Supervisor: Mr Muhammad Furqan Tanvir
}

\begin{abstract}
This research aimed at exploring the Band score in the Reading module of IELTS Academic resulting from the use of reading activities made by selected Pakistani newspaper articles in preparatory classes of IELTS Academic Reading for students of Sialkot. The condition of IELTS Academic Reading in Sialkot due to scarcity of appropriate reading input was unsatisfactory which made it hard for the students of Sialkot to gain good Band scores in this module. Therefore, the researcher gave a set of reading activities to local students of IELTS Academic Reading module. The effect of preparation through activities made by Pakistani newspaper articles on score of each participant was also investigated individually. A sample of fifteen students of IELTS Academic was selected for the study. The participants had to take reading classes which were based on these activities for thirty working days, one hour daily. Quantitative research methods were used for collecting and processing of data. A pre-test was conducted before application of activities for participants and a post-test after to measure the gain in the band score of students. Official IELTS reading material of Cambridge University Book One was used and a pre and post-test to estimate score again in reading comprehension. Lastly, a paired sample T test was applied through SPSS to figure out the discrepancies between pre-test and post-test output and results were found
\end{abstract}


statistically significant showing that activities from Pakistani newspaper articles helped IELTS Academic Reading students to improve their IELTS Academic Reading Band score.

\title{
Impact of Genre-Based Teaching on Design Report Writing
}

\author{
Researcher: Tatheer Zahra \\ Supervisor: Prof Rao Jaleel Ahmed
}

\begin{abstract}
The study explores the impact of Genre-based teaching on learner's outcome in writing forms through Design Report Writing. Various genres have been assessed and reviewed by English Language Teaching practitioners for teaching pedagogy and for assessing the learning outcome; however, no one has ventured to assess the impact of Genre-based teaching of writing on Tertiary students' design detailing in report writing formats who are learning English for a purpose, i.e., to cater the professional needs of describing a product design. The present research paper attempts to identify key factors that affect on students' academic output while learning in an EAP environment. Using experimental method, the data was elicited through Pre-tests and post-tests, classroom observations, semi structured interviews and self-assessment checklists. Semi structured interviews were conducted from Seven Language Teachers who were teaching Report writing in collaboration with Design Studio Teachers. Self-Assessment Checklist was developed to analyze the level of assimilation of Genre based Teaching in students. Students filled it after post-test was conducted. Classroom observations were recorded and interpreted using COLT A Scheme to ascertain the data. COLT A describes classroom events at the level of activity. COLT A defines the concept of classroom activity as intuitive and pedagogically meaningful. Results obtained through COLT A Scheme suggest that medium of instruction, information clarity, class environment, student behavior, class instructor, class task activity levels and student activity response level of the Experimental group was more interactive in attaining better outcome in terms of written responses than the Control group.Ten hours of teaching based on the Deconstruction, Joint Construction and Independent Construction phases of the Teaching Learning Cycle was conducted in the Experimental Group. The chief finding of the study is that Genre-based teaching through The Teaching-Learning Cycle by Feez was more effective than the traditional 10 hours teaching of PIFD students in design report writings for Design Undergraduates. Along with this,Academic skills of University Students were measured using MASUS for Use of source material-information retrieval and processing, Structure and development of answer, Control of academic writing, grammatical correctness and Qualities of presentation. Results obtained from MASUS Checklist Interpretations using One-Way ANOVA support the hypothetical stance that the post-test performance of experimental Group in Report Writing tasks was significantly better than that of the control Group. Overall, the study holds significance as it attempts to design a critical, conceptual framework for teaching Report Writing to Design Undergraduates. This research will be useful for design undergraduates studying in countries where English is considered to be a second language.
\end{abstract}




\title{
Analyzing Errors in the Use of Inflectional Morphemes by Pakistani Young Learners
}

\author{
Researcher: Maria Fatima Dogar \\ Supervisor: Prof Rao Jaleel Ahmed
}

\begin{abstract}
The research on acquisition of inflectional morphology in languages has been an area of great interest for the last 40 years. Learners that achieve a high level of proficiency in L2 feel uncertainty when it comes to grammatical inflections. The present study employs Error analysis to identify deviations from the target language and proposes the more or less problematic inflectional morphemes. The data comprised 24 creative writing journals of grade 5 students from Sicas Lahore, was analyzed manually by the researcher. The frequency and percentage were calculated in order to find the accuracy level of the English inflectional morphemes. Moreover, the scatter plots were analyzed to reflect upon the pattern of use of each inflectional morpheme by individual students. It is found that there is a wide gap in the mastery of the inflectional morphemes. The most frequent inflectional morpheme is the plural morpheme. Present participial has dominance over the other verb forms. Scatter plots of the past tense and subject verb agreement reflect that both of them are in the hypothesis testing phase of the error analysis but the frequency of past tense inflection is almost five folds to the frequency of the subject verb agreement inflection. This indicates that subject verb agreement poses more problems for the learners. The comparative degree, superlative degree and the possessive inflection have minimal occurrences but percentage accuracy is very high. That is the most striking finding of the present study.
\end{abstract}

\section{The Use of Compliment Response Strategies among Punjabi Speaking University Students}

Researcher: Summiya Azam

Supervisor: Prof Rao Jaleel Ahmed

\begin{abstract}
The use of the compliment strategies of Punjabi-speaking university students in Pakistan is investigated in the present study. The quantitative approach is used. The sample of the study is selected using non-random, purposive and convenience sampling procedures. For data collection, two Discourse Completion Tests (Urdu DCT and English DCT) have been used. The results of the study show that Punjabi-speaking university students use the same type of semantic formulaic patterns both in English and Urdu. There are no significant differences between male and female respondents (both in English and Urdu) in the use of compliment strategies. The results clearly indicate that respondents translate Urdu strategies into English, and at the same time transfer cultural trends of using more strategies for (close and equal) social distance and (equal and lower) social status and a few for greater social distance and higher social status. Moreover, the findings also exhibit that Punjabi-speaking university students only use "Agreement" strategies and avoid the use of "Disagreement" and "Request" strategies.
\end{abstract}




\title{
An Evaluation of Assessment Tools for Secondary Level English Language Classes of All BISEs of Punjab: A Cognitive Approach
}

Researcher: Muhammad Ali

Supervisor: Prof Rao Jaleel Ahmed

\begin{abstract}
The present study aims to investigate the quality of the assessment tools of English administered by BISEs in Punjab for the award of Secondary School Certificate. These assessment tools serve as the sole criterion to assess the learning of the students, therefore, their quality affects the quality of learning of the students and they have potential wash back effect on the system of education. A mixed method research design was adopted in the present study. The English language assessment tools for secondary classes of all BISEs of Punjab were evaluated with reference to the levels of cognitive domain of Revised Bloom's Taxonomy. Three raters rated the test items of these assessment tools using a rubric based on action words for each level of cognitive domain with the help of frequency tables. The consolidated data was analyzed for determining inter-rater reliability and frequency distribution along with frequency percentage. The analysis of the data revealed that most of the test items of the assessment tools were based on lower order thinking abilities and skills. The study can be beneficial for the improvement of assessment tools of English language for secondary classes of BISEs which, in turn, may lead to the improvement of the learning of the students and the education system at large.
\end{abstract}

\section{Feedback Strategies Used by Post-graduate EFL Teachers and Students, Lahore, Pakistan}

Researcher: Hafsa Karamat

Supervisor: Prof Rao Jaleel Ahmed

\begin{abstract}
The aim of the study "Feedback Strategies used by post-graduate teachers and students, Lahore", is to determine the feedback strategies GAS (Giving answer strategy) and PAS (Promoting answer strategy) of the teachers on the students' written work and the preferred strategy by the teachers and the students. Consequently, for this purpose, a pilot study was conducted to evaluate the validity of the tools used for the study. After piloting, data was collected from the concerned teachers and students and further evaluated through mix method (Convergent method). Findings were quite interesting. The teachers used GAS while checking the text but through their interview analysis PAS was their preferred choice, whereas the students preferred PAS.
\end{abstract}




\title{
Rejuvenating Lost Communication of the Patient with Aphasia through Script Training
}

Researcher: Nadir Ali

Supervisor: Dr Muhammad Shaban

\begin{abstract}
All treatment approaches for aphasic disorders that have positive outcomes are either traditional, focusing linguistic ability or functional, concentrating communicative competence. This study investigates treatment approach, script training which combines both aspects. Script training attempts to restore automatic, natural and unforced context-specific speech production for patients with Broca's aphasia.

To examine the results of script training intervention a single subject multiple baseline research design across behaviors was used to conduct the study. The purpose of this study was to explore outcomes of script training on production of intelligible scripted words, rate of speaking and errors production for single participant with severe Broca's aphasia. Script training intervention delivered in-session and via video recorded clips for home practice. The participant learned all scripts successively and achieved mastery. The probes were obtained during baseline, treatment, maintenance and generalization phases of the study for tracking the spoken use of scripted content.

The participant showed improvement on all dependent variables across all six scripts, with the largest increase in percent intelligible scripted words. Large effect size was reported for words per minute and small for errors per words. He also demonstrated functional use of learned scripts in less structured conversational context. The result of the study showed that video recorded sessions of script training added positively to the positive effects of in-session treatment. The use of selfcuing strategy, participant's motivation for treatment and severity level of disorder influenced his performance.
\end{abstract}

The findings of this study propose script training intervention as an effective therapy for rejuvenating lost communication of patients with severe Broca's aphasia.

\section{Influence of Hindi Dubbed Cartoons on the Linguistic Repertoire of Urdu/English Bilingual Children}

Researcher: Zareen Ch

Supervisor: Dr Muhammad Shaban

\begin{abstract}
The study was conducted to explore the influence of Hindi dubbed cartoons on the linguistic repertoire of the participants ranging in age from 8 years to 11 years. The intention was to trace the borrowing of Hindi words into the everyday language of the participants under study. Sixty female students of a private school; 15 from each class $2,3,4$ and 5 respectively, were selected for the study. A list of ten common words was extracted from two Hindi dubbed cartoons (Chotta Bheem and Doremon) on the basis of pilot study. The selected words of Hindi were given to the participants in English for translation from English into Urdu. The findings brought forward shift in the participants' responses regarding the use of Hindi lexemes. Class 2 participants used the
\end{abstract}


highest percentage of Hindi lexemes but the results did not mark the situation as alarming. The participants from class 5 showed the least tendency to use Hindi lexemes in their responses. The results found that the influence was transitional and temporary and with maturity and exposure towards the Urdu language, the influence of Hindi dubbed cartoons faded away from linguistic repertoire of the participants and they preferred the lexemes associating them with their speech community. Moreover, the study concluded that language contact developed a better understanding of other cultures.

\title{
Order of Acquisition of English Vocabulary by Pakistani ESL Learners of Grade I, II and III
}

\author{
Researcher: Ayesha Waheed \\ Supervisor: Dr Muhammad Shaban
}

\begin{abstract}
Language learners and teachers have always been keen to know the acquisition of words or vocabulary items both in case of first language and second language, but few bother to explore how vocabulary acquisition order and techniques can be effectively developed for grooming young learners. The purpose of this study was to find vocabulary acquisition and language maturation among young ESL learners in the light of new word learning order in terms of their cognitive process as compared to the order given in the English books published by Punjab Textbook Board. Quantitative methodology was used in this study. Grade 1, 2, and 3 students were asked to recognize differently categorized words. This study analyzed and concluded all hidden avenues with regard to natural order of learning vocabulary by young Pakistani ESL learners of initial grades, i.e., Grade I, II and III. The study covered natural order of learning English vocabulary by Pakistani ESL learners at an initial stage and it further probed into whether English text books published for these grades reflected true order of learning vocabulary or not, and the finding transpired that Punjab Textbook Board failed to demonstrate exact reflection in its English books as natural order demanded. The study was significant because it provided guidelines to teachers for effective teaching of vocabulary and the policy makers for designing appropriate curriculum and making amendments in the contents of English text books. This topic is chosen with the consideration of setting goals and objectives of excellence in ESL vocabulary at preparatory level. For young Pakistani ESL learners, it is essential to design policies and course books in the light of new orientations of vocabulary learning based on facts, verifiable and authentic research so that they may be able to learn English vocabulary without any ambiguity. The findings transpire that Punjab Textbook Board books are not following the natural order of acquisition of vocabulary in early grades like Grade 1, 2, and 3 and it needs reconsideration and review for better learning and results.
\end{abstract}




\title{
Phonological Impact of Hindi Cartoons on the Speech of Urdu/English Bilingual Children
}

\author{
Researcher: Ayesha Saddiqa \\ Supervisor: Dr Muhammad Shaban
}

\begin{abstract}
The purpose of this study was to investigate the phonological impact of the Hindi language cartoons on the speech of Urdu/English bilingual children between 5 to 10 years. The data was collected from 84 male and female participants located in Lahore. They were shown 28 images

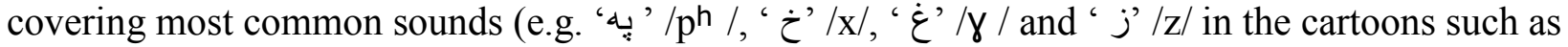
Doraemon, Motu Patlu and Abdul Bari. The participants' responses were recorded and transcribed along with English translation. Chi-square Pearson was applied to investigate the relationship between age and the use of linguistics variants. The study shows that there is significant difference between age and the use of linguistic variants. The participants who were between 5 to 6 years of age were relatively more receptive to Hindi variants. However, those who were between 7 to 10 years of age had a clear tendency for regressing towards the Urdu language. The study thus reveals that the younger the participants, the more evident are the phonological impact of the Hindi language on their speech. The study suggests that an exposure to cartoons in the Urdu language at an early age may be helpful to improve the culturally loaded vocabulary of children.
\end{abstract}

\section{Role of Attitude and Motivation in Enhancing Second Language Learners' Speaking Skills in Kotli Azad Kashmir University}

\author{
Researcher: Misbah Shahid \\ Supervisor: Dr Arshad Ali Khan
}

\begin{abstract}
This study investigated the role of attitude and motivation in the undergraduate English language learners of university of Management Science and Information Technology, Kotli Azad Kashmir. The purpose of this study was to demonstrate the relationship between attitude and motivation towards English Language learning. Attitude and motivation plays a crucial role among English language learners. Therefore it is imperative to enhance motivation in learners from the beginning. Social constructive theory was used as a conceptual framework to support this research study. Quantitative research method was utilized for data collection and analysis. The data was collected from 198 students of University of Management Science and Information Technology, Kotli, Azad Kashmir University. These students were selected with the help of simple random sampling and all of them were undergraduate students of the university. Questionnaire was used as the tool for data collection. The data was analyzed using Pearson correlation and descriptive statistics. Significant correlation was observed in the attitude and motivation of the students. The analysis of the data showed that there was a strong correlation between dependent and independent variables of the study. The findings and results of the study revealed that attitude and motivation played a major role among the undergraduate students of University of Management Science and Information Technology in learning English language. At the end, it became evident that learners' interest in English language and learners' motivational intensity influenced learners' learning.
\end{abstract}




\title{
Communicative Language Teaching Versus Transmission Models of Teaching in a Government College: An Experimental Study
}

\author{
Researcher: Maimoona Rana \\ Supervisor: Dr Arshad Ali Khan
}

\begin{abstract}
This study has been conducted to investigate the effectiveness of Communicative Language Teaching Approach in public sector colleges of Lahore. English is treated as a second language in Pakistan and Transmission Models of teaching based on Grammar Translation Method is the main approach towards ESL context in public sector colleges in Lahore. The nature of the study is experimental and is designed to trace improvement in comprehension and writing skills of low proficient English language learners at intermediate level. An Experimental group and a Control group have been used to study the effect of implementing Communicative Language Teaching Approach for this purpose. A pre-test and post-test has been carried out to measure any improvement in the students' cognitive learning process. The experimental group has been given treatment through vigorous interventions comprising Communicative Language Teaching based activities. The control group has been taught through the traditional method comprising Grammar Translation Method. The data collected from the two groups has been analyzed using SPSS. The comparative result of the experimental group and the control group shows a significant improvement in the learning process, comprehension and writing skills of the subjects of the experimental group. The analysis proves the appropriateness of Communicative Language Teaching Approach in an ESL context. It proves its effectiveness in the enhancement of comprehension and writing skills of low proficient English language learners.
\end{abstract}

\section{A Comparative Study of TBLT Approach and Traditional Approach in English Language Teaching}

Researcher: Nayab Waqas Khan

Supervisor: Dr Arshad Ali Khan

\begin{abstract}
This study has been conducted to examine the usefulness of Task based teaching method in the teaching of English language in government sector colleges of Lahore. Language teaching is never an easy job for English language teachers. The traditional method is still dominating in Pakistani colleges for teaching English and no innovations have been implemented by the educational policy makers and teachers. The traditional method has not provided fruitful results in enhancing reading comprehension skill of the students. The technique used in this study is experimental and has been designed to trace improvement in comprehension and reading skills of low proficient English learners at graduation level. Both pre-test and post-test has been conducted to measure any improvement in the students' learning process. The group of sixty learners from the local college of Lahore has been divided into two groups. The Experimental group has been given treatment through dynamic intervention comprising task based lesson plan based activities. The Control group has been taught through the traditional method encompassing Grammar Translation Method. The data collected from the two groups has been analyzed using SPSS. The proportional result of both groups (experimental and control) illustrates a substantial development in the learning
\end{abstract}


method, comprehension and reading skills of the subjects of the experimental group. The analysis verifies the suitability of task based teaching approach in an ESL context. The study shows that constructivism is the effective learning theory in which TBLT falls and thus should be implemented in colleges. It proves its effectiveness in the enhancement of reading skills of low proficient English language learners.

\title{
Examining 'Washback Effect' Via Bloom's Taxonomy in a Private Pakistani School
}

Researcher: Ayehsa Malik

Supervisor: Dr Nadia Anwar

\begin{abstract}
The aim of the study is to investigate the existence and intensity of washback effect in a selected private school in Lahore. The curriculum of the school is both subscribed and assessed by an international body called Cambridge International Examinations (CIE). Keeping and acknowledging the significance of English as a Second Language (ESL), this qualitative study targets the English teachers of Grades $7-11$. Three observations were conducted for each teacher, preceded and followed by pre and post observation meetings where they were briefed and their concerns were addressed. Along with the details of educational and professional backgrounds, lesson plans were taken from each teacher and Teacher Observation Checklist was used, adapted from a book used in Cambridge trainings. The focal point of the class observations was Reading Comprehensions which were later discussed in the light of curriculum guidelines and specimen papers attached at the end. With the use of Microsoft Excel, results were analyzed which not only proved the existence of washback but highlighted the intensity of it. Apart from this, differences in teaching practices were also interpreted in terms of inapt educational backgrounds and active involvement in professional development.
\end{abstract}

\section{Animated Cartoon movies: An Innovative and Effective Teaching and Learning Tool in Enhancing the English Story Writing Skills}

\author{
Researcher: Zara Saleem \\ Supervisor: Dr Nadia Anwar
}

\begin{abstract}
In Pakistan English language learners face many difficulties while they pass through the process of learning another language. Especially, it is very difficult for the children to keep in mind all the rules of language use at an early age. In order to facilitate language learning in particular, story writing skills, this study aims to target students'/subjects' creativity through inspirational and interesting animated cartoon movies. During the study the learners are given a free hand to formulate an expression devoid of reluctance towards learning the language and its rules.
\end{abstract}

An experimental and purposive sampling technique was used to find out the effect of animated cartoon movies on students' story writing skills. After making the female students of grade VIII of a semi-government school watch cartoon movies, a series of story writing tests including a pre and post-test was conducted to find out its effect on English language learning. These tests were 
assessed on four different criteria including the assessment of language, vocabulary use, organization, and narrative techniques. The results of these scoring rubrics consisted of five points which were shown through graphic and numeric presentations.

\title{
Oral Skills Development in Group Work Dynamics
}

\author{
Researcher: Rizm Ul Zafar \\ Supervisor: Dr Maria Maldonado
}

\begin{abstract}
This dissertation aims to explore how group work may be effectively utilized as part of the classroom dynamic to aid in developing oral English language skills. Specifically, we will look at one hundred under-privileged students studying English in the US funded English Access Microscholarship Program in Kasur District. In recent educational research, there has been a great emphasis on the impact that group work can have on students' confidence, improving it to the point where they can exhibit their abilities without the interference or assistance of the teacher. The present exploratory study follows quasi-experimental methods to investigate the impact of group work on the speaking skills of these Access students over a period of three months. The data has been collected through a pre-test and a post-test and two survey questionnaires designed for both the Access students and their English language teachers. We have adopted an objective approach to analyze and describe the data statistically. The major finding indicates that if group work is included in the classroom dynamic while teaching L2 speaking skills in PELT context, language teachers can raise the confidence and fluency of their students both in a classroom setting and social discourse. To conclude, if institutes and ELT experts put more emphasis on group formation in the classroom, students' fluency in L2 can be considerably enhanced.
\end{abstract}

\section{A Study of Government Teachers' Beliefs about L2 Grammar Teaching at Secondary Level}

\author{
Researcher: Sadia Nazar \\ Supervisor: Dr Usman Khalil
}

\begin{abstract}
There is a general agreement among researchers that the beliefs of teachers play an important role in successful L2 acquisition. The current study was also conducted to evaluate the impact of teachers' beliefs about English language teaching methodologies employed at secondary level in Pakistan. The aim of the study was to explore the kinds of beliefs teachers had and to discover the impact of those beliefs on language teaching methodologies. The participants of the study included teachers who taught English at secondary level in both public and private sector. The study was quantitative in nature. A total of 100 teachers from 25 schools were selected as sample for the study. Simple random sampling was used as the sampling technique. 76 responses were obtained and analyzed using SPSS. Data was cleaned and missing values were imputed. Some new variables were created using the recoding facility of SPSS. Data analysis involved descriptive statistics, independent $t$ test analysis and ANOVA. The study found that the majority of teachers relied on the beliefs inherited from older teachers about the teaching of English grammar and these beliefs were transferred from one generation to the next. Surprisingly, there was a significant difference
\end{abstract}


between the beliefs of the married and unmarried teachers about the teaching of English grammar. Hence, the researcher concluded that teachers' belief about English language learning were not uniform among the teachers. However, no significant difference was found in the beliefs of teachers working in public and private sectors. 
Linguistics and Literature 


\title{
The Stylistic Analysis and Comparison of the Protagonists in 'Don Quixote' and 'Sorrows of Young Werther' and Their Socio- Cultural and Stylistic Effects
}

\author{
Researcher: Zujajah Naqvi
}

Supervisor: Dr Asim Karim

\begin{abstract}
Miguel de Cervantes is a great Spanish writer. His influence on the Spanish language has been so great that the language is often called la langue de Cervantes ("the language of Cervantes"). His novel; 'The Ingenious Gentleman Don Quixote of La Mancha' is considered to be the first modern European novel, is a classic of Western literature, and is regarded amongst the best works of fiction ever written. The protagonist of the novel 'Don Quixote' became very popular and had a great cultural, social, artistic and linguistic impact. The Quixotic effect influenced the society and arts greatly. Similarly, Johan Wolfgang Von Goethe was a great German Writer. The classical novel; 'Sorrows of Young Werther' was the first and was the most significant masterpieces of Goethe and it contributed to the Sturm and Drang literary movement in German literature. The protagonist; Werther also became very popular and had great cultural, social and artistic impacts. The Wertherfever; a term given by Napoleon Bonaparte, had a great impact on society and arts so much so that youngsters were emotionally influenced by 'Werther' and dressed like him; they even committed suicides like him. The present study focused on the literary stylistic analysis of the language of the two protagonists; Don Quixote and Werther. The main objectives of the research were to discover: 'What are the different lexical field categories (exclamatives, adjectives, adverbs, nouns, intensifiers; quantifiers, qualifiers and verbs) used in the selected dialogues of Don Quixote and Sorrows of Young Werther? And what is the intensity of using each lexical category in both the novels? What are the different important vocabulary items used in the novels? What are their meanings? What is the comparison of proper nouns and common nouns' vocabulary items in both the novels ('Don Quixote' and 'Sorrows of Young Werther'). How did the great novels 'Don Quixote' and 'Sorrows of Young Werther' become so popular and legendary and which vocabulary words (lexical items) of Proper Nouns (of famous names, terms and historical characters) made them classical novels? What is the lexical stylistic analysis? How the vocabulary items and lexical categories as: exclamatives, adjectives, adverbs, nouns, intensifiers and verbs contribute towards the emotional and loaded language of the protagonists? What is the comparison of emotional language of Don Quixote and Young Werther? What is the literary stylistic analysis of 'Don Quixote' and 'Sorrows of Young Werther' and how can we compare the novels stylistically? What language made the protagonists of the two novels so effective socially and culturally? And 'What affects the two novels had on society and culture of arts?' The novels were completely studied and analyzed to find out and calculate the use of proper nouns references used by the Protagonists. Apart from that, 200 dialogues used by each of the protagonists (Don Quixote and Werther) were randomly selected from both the novels and were stylistically analyzed and compared according to the stylistic analysis model given by Geoffrey N. Leech and Micheal H. Short (1981) and Professor Ismail S. Talib (2005). It was found out through mixed method (qualiquantitative analysis) that Don Quixote became famous because of his rich use of language and wise and proverbial sayings referring to all the world and life whereas Young Werther became popular because of his extremely emotional and flowery language. Both the protagonists had a strong impact on society and culture of arts because of their unique style of language. It was
\end{abstract}


concluded finally that 'The language of 'Don Quixote' has greater use of subject tools, rich vocabulary; proper nouns and connotative references, greater use of intensifiers; more intensity, adverbial and action vocabulary richness whereas Werther's language is simpler and less intense; it uses lesser adverbs, lesser intensifiers, lesser nouns, much lesser proper nouns but it uses much more verbs and exclamatory expressions that makes its' language much more emotional and moving as compared to Don Quixote whose language is practical, witty and proverbial.'

\title{
Foregrounded Irregularities in Perveen Shakir's Poems
}

\author{
Researcher: Kanwal Shahzadi \\ Supervisor: Dr Asim Karim
}

\begin{abstract}
In stylistic analysis, foregrounded irregularities play a vital role in removing the ambiguity and obscurity in any piece of literature especially poetry. In this study, the researcher has analyzed eight poems by Perveen Shakir, with a particular focus on four deviations namely semantic deviation, graph logical deviation, dialectical deviation and register deviation within the stylistic analysis. The analyses of the poems reveal that stylistics, linguistics and language as well as literary criticism and literature are inter-linked. In addition to this, the carefully study of the selected poems helps the readers to find deeper meaning and new dimensions into appreciating the literary works.
\end{abstract}

\section{A Stylistic Analysis of Hanif Qureshi's The Budhha of Suburbia}

\author{
Researcher: Asia Majeed \\ Supervisor: Mr Muhammad Furqan Tanvir
}

\begin{abstract}
Stylistic analysis is a technique to examine and analyze the linguistic devices used by an author in a literary piece of art. Researchers conduct stylistic analysis of literary works such as novels, poems or any other form of fiction to get a deep understanding of the work of the fiction writer. Writers use linguistic mediums like metaphors, juxtaposition, similes, personification, humor, satire, irony and specific lexical compositions to achieve some literary effect in their fictional work. The researcher has chosen a popular contemporary fictional work of Hanif Kureishi 'The Buddha of Suburbia' for stylistic analysis. The purpose of the research work is to examine the linguistic features of the novel through stylistic analysis. Buddha of Suburbia is a contemporary novel, which explores various themes. Some of the themes of the novel include racial discrimination in the British society, youth culture, and identity crisis among the secondgeneration immigrants, frustrations of the young people, difference between the old and new traditions, clash of eastern and western culture and the disillusionment of the young generation with the established norms of the society. Qualitative methodology is used in the research study and the sample for the study is the novel The Buddha of Suburbia. All the chapters in the novel have been studied thoroughly and linguistic and stylistic features have been recorded and analyzed. The results of stylistic analysis determine that Hanif Kureishi uses various stylistic devices like juxtaposition, colloquialism, metaphors, exclamatory sentences, irony and humor in the novel to establish his story. All these features make the story comical and satirical. There is a single narrator of the story. The research thesis reveals that the writer has used colloquialism and exclamatory
\end{abstract}


sentences to add the element of realism to the novel. The research study will help English language students in analyzing the stylistic features of a literary text or composition. It will also help future researchers in their field of study. People interested in Hanif Kureishi's works will able to comprehend his writings and they will be able to appreciate his works more. The research will also help linguistic students in understanding the various patterns of linguistic devices. Limitations and future research directions have also been discussed in this research study.

\title{
Bakhtin beyond the Novel: Heteroglossia, Carnival and Dialogism in "Waiting for Godot"
}

\author{
Researcher: Sobia Ilyas \\ Supervisor: Dr Muhammad Shaban
}

\begin{abstract}
The study aims to explore Bakhtin's theories: Heteroglossia, Carnival and Dialogism in wider contexts by enlarging upon their role in the novel and giving them broader applications. In doing so, they are effectively applied to Samuel Beckett's play, 'Waiting for Godot', proving their worth in a genre as diverse as, The Theatre of The Absurd, which possesses none of the structural finesse and the stylistic beauty of the novel. The study draws upon Bakhtin's traditional use of Heteroglossia: as a tool for examining the contentious voices of polyphonic novels and enlarges it to explore the voices that denote the dynamics of social systems: power, resistance, identity and solidarity in Waiting for Godot. Bakhtin and Becket are brought together on the basis of their shared ideologies and language philosophies. The most prominent being their notion of voices, as being independent but fusible and their belief in the unfinalizibilty of all forms of art and life. A collaboration of Bakhtin and Beckett prove enriching for both writers. It gives a broader vision to Beckett's existentialist views. Contrary to the pessimism usually associated with him, we see a progressive aspect of Beckett's ideology, in his elevation of man and in his anticipation of hope and betterment for the world. The collaboration also proves empowering for Bakhtin, in displaying his influence over areas such as Cultural Studies, Sociolinguistics and Anthropology. It is hoped that the study will contribute to Bakhtin's rising status in the field of Sociolinguistics and prove his theories to be effective approaches to Discourse Analysis.
\end{abstract}

\section{Preserved Versus Subverted Stereotypes of the East - West Binary in Mohsin Hamid's The Reluctant Fundamentalist (2007)}

Researcher: Muhammad Hayat

Supervisor: Dr Elisabeta Zelinka

\begin{abstract}
The present thesis aims to study the evolution of the two oppositional blocks of the East - West stereotypes, as presented by Mohsin Hamid in his 2007 novel, The Reluctant Fundamentalist, through the conceptual framework of Critical Discourse Analysis, theories of postmodern philosophy, and core elements of Orientalism.
\end{abstract}

The present MPhil project attempts to answer the following research questions: which of the East - West stereotypes does Mohsin Hamid preserve and which ones he subverts, what are the effects 
of the auctorial devices on the culturally stamped audience, what is the role of nostalgia in Hamid's message and how does it connect to his two other auctorial techniques, the frame story technique (the miseen abyme technique) and the dramatic monologue technique?

Therefore the study draws its conclusions based on the research questions. The 'Opposite'/the 'Other' geo-political and cultural hemisphere are constantly (mis)judged in terms of these stereotypes. Consequently, a lot of (mis)representing imagery is created and erroneous judgments, tensions and even aggression between the East and the West. These global-scale socio-political stereotypes create a misleading, erroneous discourse which dramatically influences the everyday, micro-scale individual and his identity crises. This is what I intend to investigate in my MPhil thesis. The discourse of The Reluctant Fundamentalist, 2007 is compared and contrasted with the discourse articulated by the Occidental literature, music, paintings and films, cartoons and literary works the same issue.

As a result of the investigation, it has been discovered that the East is misrepresented by the discourse deployed by the Occident for the Orient. The Occidental literature, music, paintings, films and cartoons present the Orient as weak, backward, mad, colonized, and with less technology.

The author of this project wants to conduct some interviews and future researches can be conducted on the differences and oppositional impacts of such literary stereotypes in terms of age, socioeducational background, and exposure to other cultures.

\title{
The Reluctant Fundamentalist: Identity Crises from the Global-Level to the Inter-Personal Scale
}

\author{
Researcher: Kausar Mushtaq \\ Supervisor: Dr Elisabeta Zelinka
}

\begin{abstract}
This research aims to complete a critical - analytical analysis of the central characters' micro-scale identity crises, as influenced by the macro-scale, global political events of 9/11, 2001, in Mohsin Hamid's novel The Reluctant Fundamentalist (2007). The conceptual framework of the present research work is Norman Fairclough's Critical Discourse Analysis (CDA), blended with the core theories presented by Samuel P. Huntington in The Clash of Civilizations and the Remaking of World Order (1996), by Edward W. Said in Orientalism (1978) and in "The Clash of Ignorance" (2001).

The present MPhil study is an attempt to answer the following research questions: "What are the different frustration levels that (re)shape the characters' identities and trigger their identity crises?", "Which sector of identity is influenced and /or altered most due to different levels of different frustrations - analyzing the central characters?" and "How does the micro level, crisisladen relationship between Erica and Changez mirror the global, macro level relationship between the West (the USA) and the East (Pakistan)?".

Therefore, the conclusion is drawn on the basis of the above-mentioned research questions. All individual characters, living in either the Western or in the Eastern hemisphere are deeply influenced by the macro-scale event of $9 / 11$ and they undergo serious identity crises. The cultural
\end{abstract}


differences create stereotypes, misconceptions and tensions between the Oriental and Occidental characters. Consequently, an "us" versus "other" friction appears and the main character has no other choice but to return to his native country, identity and family in Pakistan.

The novel is constructed in the form of the frame story technique, the frame story is in fact the main character's narration of his life events and his listener is a mysterious American interlocutor, who never speaks directly to the readers. The ending of the novel is an open ending, challenging the reader to imply his / her imagination and to construct the possible closing scenes.

My future line of research will focus on the reasons behind the author's choice to apply the frame story technique. Secondly, I wish to complete a contrastive analysis of the trope of identity crises in other similar artistic creations (novels, films), that also focus on the psycho-social impact of the 9/11 events upon Occidental versus Oriental characters, in terms of different age groups or sociocultural backgrounds. 


\section{MPhil Thesis Supervised by Faculty}

(Year Wise)

\begin{tabular}{|c|c|c|c|c|c|c|c|}
\hline No & Name & Abbreviation & Area of Interest & 2015 & 2016 & 2017 & Total \\
\hline 1 & Prof Rao Jaleel Ahmed & RJA & $\begin{array}{c}\text { Psycholinguistics, Semantics and } \\
\text { Applied Lexicology }\end{array}$ & 02 & 08 & 08 & 18 \\
\hline 2 & Dr Maria Maldonado & MM & $\begin{array}{l}\text { Lexicology, Second Language } \\
\text { Acquisition, Discourse Analysis } \\
\text { and Language Policy }\end{array}$ & - & - & 01 & 01 \\
\hline 3 & Dr Muhammad Shaban & MS & Language, Media and Discourse & 04 & 11 & 15 & 30 \\
\hline 4 & Dr Nadia Anwar & NA & $\begin{array}{l}\text { African Theatre and Drama, } \\
\text { Adaptation Studies, Critical } \\
\text { Discourse Analysis }\end{array}$ & - & 01 & 05 & 06 \\
\hline 5 & Dr Arshad Ali Khan & AAK & Morphosyntax & - & 03 & 05 & 08 \\
\hline 6 & $\begin{array}{c}\text { Mr Muhammad Furqan } \\
\text { Tanvir }\end{array}$ & MFT & $\begin{array}{c}\text { English Literature, Critical } \\
\text { Discourse Analysis }\end{array}$ & - & 02 & 02 & 04 \\
\hline 7 & Dr Elisabeta Zelinka & EZ & Multiculturalism & - & - & 03 & 03 \\
\hline 8 & Dr Nazir Ahmad Malik & NAM & Syntax, Sociolinguistics & 04 & 04 & 01 & 09 \\
\hline 9 & $\begin{array}{c}\text { Dr Muhammad Athar } \\
\text { Khurshid }\end{array}$ & MAK & $\begin{array}{c}\text { Syntax, Second Language } \\
\text { Acquisition }\end{array}$ & - & 03 & 04 & 07 \\
\hline 10 & Dr Asim Karim & $\mathrm{AS}$ & $\begin{array}{l}\text { Literature and Multiculturalism, } \\
\text { English Language Teaching }\end{array}$ & 02 & 01 & - & 03 \\
\hline 11 & Mr Shahzad Ahmad & SA & \begin{tabular}{|} 
Phonetics \& Phonology, \\
Morphology \& Syntax, Lexicology \\
\& Lexicography
\end{tabular} & (1) & 0 & 0 & 00 \\
\hline 12 & Dr Sarmad Hussain & $\mathrm{SH}$ & Urdu Phonetics \& Phonology & 01 & 01 & - & 02 \\
\hline 13 & Dr Nasir Abbas & $\mathrm{NA}$ & Second Language Acquisition & - & 01 & - & 01 \\
\hline 14 & Dr Usman Khalil & UK & $\begin{array}{l}\text { English Language Teaching, } \\
\text { Language Education }\end{array}$ & 01 & - & 01 & 02 \\
\hline & Total & & & 14 & 34 & 44 & 94 \\
\hline
\end{tabular}




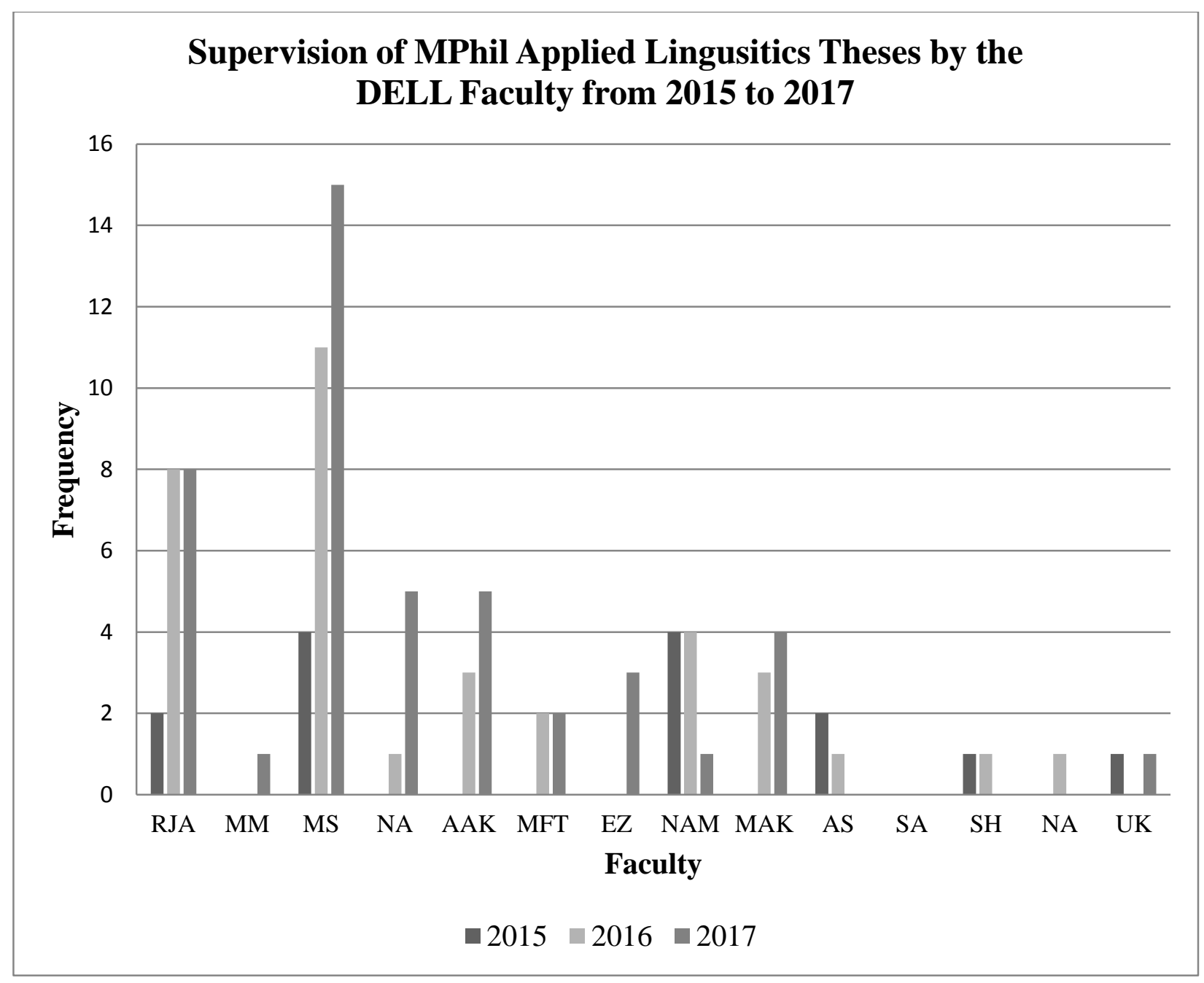



10

I have found the abstracts included in The Abstract Book of Linguistic Research 2015-17 to the point and easy to read. Given my background in nuclear physics, I did not have a good idea about the research conducted in the discipline of linguistics. However, this abstract book has made all the difference and I now have a fairly good idea of what it means to do research in linguistics, what kind of research is being done, and what are the applications of this research especially within the Pakistani context. I am glad to find out that linguistic research done at the Department of English Language and Literature, UMT is just as thought provoking, precise and applicable as the research done in any other discipline taught at UMT or any other institute across the globe and meets all the scientific criteria of excellence.

\section{Dr Muhammad Aslam}

Rector

University of Management and Technology

01

The first issue of The Abstract Book of Linguistic Research 2015-17 is an output of the years of efforts

spent in establishing the Department of English Language and Literature and giving it a research orientation. The credit goes to the editors and even more so to the students who did the research listed in this abstract book. It shows the variety and diversity of topics being explored at the Department. It also reveals the practical applicability of the research carried out, how it may lead to defining the complex linguistic landscape of Pakistan, where language is considered a mark of identity, a basis of politics and solution of various language related problems, such as; pedagogical and political. The clarity and quality of the abstracts show the high standards of research maintained at the Department, commitment of the

faculty and hard work of the students who strive to achieve excellence in their work. I wish the department a great success and congratulate the team for compiling and publishing research undertaken by post-graduate students.

\section{Dr Rukhsana Kausar}

Dean, School of Social Sciences and Humanities University of Management and Technology

Lahore Campus: UMT Road, C-II, Johar Town, Lahore - 54770, Pakistan Tel: +92 $4235212801-10$, Fax: +92 4235212819

email:admissions@umt.edu.pk

UAN: 042111300200

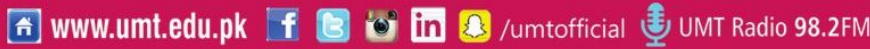

